\title{
Modelling larval dispersal of the king scallop (Pecten maximus) in the English Channel: examples from the bay of Saint-Brieuc and the bay of Seine
}

\author{
Amandine Nicolle ${ }^{1,6,{ }^{*}}$,Franck Dumas ${ }^{2}$,Aurélie Foveau ${ }^{3}$,Eric Foucher ${ }^{4}$,Eric Thiébaut ${ }^{1,5}$
}

\author{
${ }^{1}$ Station Biologique de Roscoff, Adaptation et Diversité en Milieu Marin, UMR 7144, CNRS, 29680, Roscoff, \\ France \\ ${ }^{2}$ Département DYNECO, Technopole Brest-Iroise, IFREMER, BP70, 29280, Plouzané, France \\ 3 Laboratoires Environnement Littoral \& Ressources Aquacoles Finistère-Bretagne Nord, CRESCO-IFREMER, \\ BP 70 134, 35801, Dinard, France \\ ${ }^{4}$ Laboratoire Ressources Halieutiques, IFREMER, Avenue du Général de Gaulle, BP 32, 14520, Port-en-Bessin, \\ France \\ ${ }^{5}$ Station Biologique de Roscoff, UMR 7144, UPMC Univ Paris 06, 29680, Roscoff, France \\ ${ }^{6}$ Pôle STIC/OSM, ENSTA Bretagne, 2 rue François Verny, 29806, Brest cedex 9, France
}

*: Corresponding author : Amandine Nicolle, email address : amandine.nicolle@ensta-bretagne.fr

\begin{abstract}
:
The king scallop (Pecten maximus) is one of the most important benthic species of the English Channel as it constitutes the first fishery in terms of landings in this area. To support strategies of spatial fishery management, we develop a high-resolution biophysical model to study scallop dispersal in two bays along the French coasts of the English Channel (i.e. the bay of Saint-Brieuc and the bay of Seine) and to quantify the relative roles of local hydrodynamic processes, temperature-dependent planktonic larval duration (PLD) and active swimming behaviour (SB). The two bays are chosen for three reasons: (1) the distribution of the scallop stocks in these areas is well known from annual scallop stock surveys, (2) these two bays harbour important fisheries and (3) scallops in these two areas present some differences in terms of reproductive cycle and spawning duration. The English Channel currents and temperature are simulated for 10 years (2000-2010) with the MARS-3D code and then used by the Lagrangian module of MARS-3D to model the transport. Results were analysed in terms of larval distribution at settlement and connectivity rates. While larval transport in the two bays depended both on the tidal residual circulation and the wind-induced currents, the relative role of these two hydrodynamic processes varied among bays. In the bay of SaintBrieuc, the main patterns of larval dispersal were due to tides, the wind being only a source of variability in the extent of larval patch and the local retention rate. Conversely, in the bay of Seine, wind-induced currents altered both the direction and the extent of larval transport. The main effect of a variable PLD in relation to the thermal history of each larva was to reduce the spread of dispersal and consequently increase the local retention by about $10 \%$ on average. Although swimming behaviour could influence larval dispersal during the first days of the PLD when larvae are mainly located in surface waters, it has a minor role on larval distribution at settlement and retention rates. The analysis of the connectivity between subpopulations within each bay allows identifying the main sources of larvae which depend on both the characteristics of local hydrodynamics and the spatial heterogeneity in the reproductive outputs.
\end{abstract}

Keywords: King scallop ; English Channel ; Numerical model ; Lagrangian transport ; Planktonic larval duration ; Swimming behaviour 


\section{Introduction}

The knowledge of larval dispersal processes that control larval export from local population and population connectivity is critical to define effective strategies of spatial fishery management, i.e. to delineate spatial management units and to design protected subareas like fishing closures (Fogarty and Botsford 2007). While larval dispersal results from complex interactions of hydrodynamics with spawning period, planktonic larval duration and active larval behaviour, quantifying dispersal and connectivity among marine benthic populations remains a major challenge in marine ecology. Recently, significant progresses have been made following methodological developments including biogeochemical markers, genetic markers and numerical hydrodynamic models (see reviews in Palumbi 2004; Levin, 2006; Cowen and Sponaugle 2009). Although no single methodology provides a complete picture of dispersal and connectivity across spatial and temporal scales, one obvious advantage of larval dispersal modelling is that models allow for multiple releases of virtual larvae through time and space, thereby capturing the expected effect of environmental variability on larval dispersal and connectivity. In addition, through inferential approach, numerical models can be used to quantify the relative role of hydrodynamics and life history traits on dispersal. Although numerical models are highly variable in terms of complexity, Lagrangian models that compute individual pathways of biologically active particles in complex oceanographic patterns are now widely used (see review in Miller 2007).

Largely distributed along the Northeast Atlantic coasts, from the north of Norway to the Iberian Peninsula, off the North-western coast of Africa, in Canaries, Azores and Madeira, and in the Mediterranean Sea, the king scallop, Pecten maximus, is particularly abundant in the ICES division VII around the British Isles, and more specifically in the English Channel (Quéro and Vayne 1998; Brand 2006). In this latter area, it is among the most valuable benthic invertebrates which constitute the first exploited resource in landings in terms of volume and economic value for the French fleet based in this maritime area (Guitton et al. 2003). Despite its high commercial interest, knowledge on scallop dynamics are mainly based on local studies (e.g. Thouzeau and Lehay 1988; Chauvaud et al. 1998) and several points including larval dispersal remain insufficiently known for the setting up of a management policy at a regional level. In particular, field observations and direct estimates on larval 
transport are non-existent according to the difficulties to identify bivalve larvae at the specific level (Paugam et al. 2003). Despite this lack of knowledge, some informations on Pecten biology are well documented in particular the importance of temperature and swimming larval behaviour.

Temperature has a strong influence on larval dispersal and recruitment of scallop by affecting adult sexual maturation (Paulet et al. 1988, 1992) and planktonic larval duration (PLD) (Beaumont and Barnes 1992; Cragg 2006). The reproductive process varies among localities in the Channel. In the bay of Saint-Brieuc, a synchronous maturation of all the individuals, starting in February or March, results in a massive spawning in early summer when the water temperature reaches about $16^{\circ} \mathrm{C}$. This first spawning event concerns about 40 to $60 \%$ of individuals while a second spawning event concerning all the individuals occurs 2 to 3 weeks later (Paulet and Fifas 1989). In other coastal embayments like the bay of Seine or the bay of Brest, the interindividual synchronism in the gametogenesis is low; partial spawning are then reported from May to October with a maximum in July-August (Paulet et al. 1988; Lubet et al. 1987). While mean planktonic larval duration of scallop is around one month (Le Pennec et al. 2003), variations with temperature have been reported from laboratory experiments (Cragg 2006) and can affect simulated larval dispersal. Assuming that a shorter PLD reduced dispersal distances and larval export (Shanks et al. 2003), one can expect changes in larval dispersal over the spawning season in relation with the spatial and temporal variations in temperature.

Despite the weak swimming abilities of planktonic bivalve larvae, commonly below $2.3 \mathrm{~mm} \mathrm{~s}^{-}$ ${ }^{1}$ (Chia et al., 1984), recent studies emphasize the influence of larval behaviour on the direction and extent of larval dispersal, transport success and the degree of connectivity between subpopulations because of vertical shear in the currents (e.g. North et al. 2008; Gilbert et al. 2010). While the behaviour of Pecten maximus larvae is poorly known, laboratory observations describe different phases of swimming behaviour during larval development from hatching to settlement (Cragg 1980). First, trochophores and early veligers swim continuously upwards and tend to accumulate at the surface. Afterwards, veliger and pediveliger larvae alternately swim up following a helical swimming path and sink by retracting their velum and closing their shelf valves. The relative duration of swimming and sinking behaviour as well as swimming velocity change over time; larval accumulation 
in surface waters is then less pronounced as larvae become older and pediveliger larvae tend to concentrate close to the substrate.

In this context, the goal of the present study is to develop a coupled biophysical model to investigate the influence of the main processes involved in scallop larval dispersal in the English Channel by focusing on the bay of Saint-Brieuc and the bay of Seine which harbour the two major fishing grounds of scallop in the study area. Following the development of a coupled particle-tracking and hydrodynamic model, the main objectives are (1) to assess the intra- and inter-annual variability on larval dispersal in relation to environmental variability, (2) to quantify the influence of biological factors (i.e. reproductive output, spawning date, planktonic larval duration, larval vertical behaviour) on the dispersal of scallop larvae and the intra-stock connectivity.

\section{Material and methods}

\subsection{Geographical setting}

In the English Channel, hydrodynamics are mainly governed by strong instantaneous tidal currents because of the particular topography of the shelf that amplifies the tidal wave during its progression from west to east (Pingree 1980). Residual currents due to the non-linearity in the tidal signal are generally one order of magnitude lower, i.e. below $5 \mathrm{~cm} \mathrm{~s}^{-1}$, except locally around bathymetric asperities of the northern coast of Cotentin where they exceed $20 \mathrm{~cm} \mathrm{~s}^{-1}$ (Salomon and Breton 1993). These authors note a mean current from West to East and the occurrence of permanent or transitory coastal eddies which result either of the tidal motion rotating around islands or of capeeffects. Permanent gyres are well developed in the Saint Malo gulf around the Channel Islands (Jersey, Guernesay, Alderney, Chausey). The wind regime of Channel Sea is characterized by two dominant directions: West-Southwestward and East-Northeastward (Fig.1). Although tidal residual currents are part of the long-term water mass transport in the English Channel, wind can also play a significant role on circulation at weeks scale and greatly influence larval dispersal by amplifying or counteracting tidal residual currents (Salomon and Breton 1993; Ayata et al. 2009). Density gradients due to temperature and salinity differences are another driving mechanism for water motions which produces three dimensional velocity structures. Because of the intense tidal vertical mixing and the low river run-off 
at spawning period, their effects are only significant in the western entrance of the Channel where a seasonal thermocline and a thermal bottom front are observed (Le Boyer et al. 2009) and in the vicinity of the Seine estuary because of large water discharge: the average river flow is $450 \mathrm{~m}^{3} \mathrm{~s}^{-1}$ and ranges from $100 \mathrm{~m}^{3} \mathrm{~s}^{-1}$ in summer up to $2000 \mathrm{~m}^{3} \mathrm{~s}^{-1}$ in winter. (Salomon and Breton 1993; Cugier and Le Hir 2002). Currents linked to the strongly stratified plume with strong baroclinicity are of the order of $10 \mathrm{~cm} . \mathrm{s}-1$ at the mouth of Seine (Cugier and Le Hir, 2002). No saline or thermal stratification was reported in the bay of Saint-Brieuc.

The bay of Saint-Brieuc and the bay of Seine are located in the southern part of the English Channel and harbour the most important scallop beds in this area (Fig.2). Scallop populations in both bays are monitored by Ifremer following a spatially stratified random sampling design since 1986 (Fifas 1993) and 1990 (Vignaud et al. 2001) respectively. The different stratums were defined according to the scallop distribution, the nature of sediment and the distance from the main harbour: 6 stratums were defined in bay of Saint-Brieuc and 5 in bay of Seine. These stock surveys provide the stock size as well as the age and size structure of the targeted population on areas of $634 \mathrm{~km}^{2}$ for the bay of Saint-Brieuc and $2484 \mathrm{~km}^{2}$ in the bay of Seine. For the bay of Seine, the annual production represents 3000 to 10000 tons while for the bay of Saint-Brieuc, the production varies between 2500 and 6800 tons for about 250 ships (Fifas 2004). Thanks to these surveys, the relative importance of each stratified area to the total reproductive output has been evaluated for both bays (Fig. 2-b, c, d). First, at each sampling station, densities of each age class were calculated from the abundances data and standardized to $1 \mathrm{~km}^{2}$. Second, in GIS, a spatial join allows to affect each sampling station to the corresponding stratified area and to calculate a mean value of scallop densities per stratified area. Third, the relative importance of each stratum was estimated by dividing the density values per stratified area by the total densities of King Scallop in each bay. For the present study, the calculations were conducted only on selected ages, i.e. two year old and later, corresponding to sexually mature individuals (Paulet and Fifas 1989) from data covering the recent period (2000 to 2010). For each bay, the mean density of mature scallops per strata (ind. $\mathrm{km}^{-2}$ ) for the period 2000-2010 and the relative contribution of each stratum to the total adult stock are reported on Fig. 2. 
The bay of Saint-Brieuc is characterized by the strong presence of the invasive gastropod species, the slipper limpet Crepidula fornicate which is a spatial and trophic competitor of Pecten maximus (Thouzeau et al. 2000). Native from the Atlantic coast of the USA, it has been accidentally introduced in Europe at the end of the $19^{\text {th }}$ century with American oysters and reported in the bay of Saint-Brieuc since the mid-70s (Blanchard 1997). In the early 90s, its biomass reaches now more than 250000 tons and the population covered about $25 \%$ of the bay, mainly in its western part (Hamon and Blanchard 1994). In response to the exponential development of the Crepidula population, the barycentre of the scallop stock moved gradually towards the North and the East of the bay (Fifas pers. Obs.). To assess the influence of Crepidula proliferation on larval dispersal and connectivity within the bay of Saint-Brieuc, the relative importance of each stratum on the adult scallop stock and the reproductive output was also determined for the period 1991-1999 (Fig. 2-b).

\subsection{Numerical model}

\subsubsection{Hydrodynamic model}

Modelling is performed using MARS-3D (3D hydrodynamic Model for Applications at Regional Scale, Ifremer), a 3D primitive equation-free surface model applying the Boussinesq approximation and hydrostaticity (see a detailed description in Lazure and Dumas 2008). Spatial discretisation is achieved using a staggered "C" grid and sigma vertical coordinates. Temperature and salinity evolution are computed through the simulations. The turbulent closure scheme used to compute the vertical turbulent diffusion coefficient is the $\mathrm{k}-\mathcal{E}$ model. In order to maintain horizontal mesoscale structures, horizontal viscosity is computed using a formulation proposed by Smagorinsky (1963), and dependent on local mesh dimensions and velocity gradients.

MARS-3D model has been validated in the Bay of Biscay from satellite observations of sea surface temperature (Lazure et al. 2009) and also from data of sea surface elevation and currents (Lazure and Dumas, 2008). It has been successfully used for different Lagrangian applications including the larval transport in various hydrodynamical contexts like the Bay of Biscay (Ayata et al. 2010; Huret et al. 2010) and the western Mediterranean Sea (Nicolle et al. 2009), or the development of a phytoplanktonic bloom of Dinophysis (Velo-Suarez et al. 2010). 
For the purpose of this study, Mars-3D is used in a 'English Channel' configuration with a domain ranging from $48^{\circ} \mathrm{N}$ to $51^{\circ} \mathrm{N}$ in latitude, and from $7^{\circ} \mathrm{W}$ to $2^{\circ} \mathrm{E}$ in longitude, and with a horizontal resolution of $2 \mathrm{Km}$. Thirty sigma layers are used with thinner layers near the surface. This model (i.e. level 1) is embedded in a larger model (i.e. level 0) which encompasses the whole Bay of Biscay and the North Sea. Meteorological conditions necessary to compute momentum and heat exchanges were obtained from the ARPEGE analysis (spatial resolution of $0.5^{\circ}$ and temporal resolution of 3h) of METEOFRANCE. The tidal forcing was obtained from FES2004 solution (Lyard et al. 2006) for the level 0 and computed from level 0 along the open boundaries of the level 1. Discharges of main rivers, which drives mostly the salinity in the domain, were obtained from historical time series at daily frequency by the Frenchwater office database (http://www.hydro.eaufrance.fr/).

Larval trajectories were calculated in three dimensions for each time step from the velocity fields computed by the hydrodynamic model. The advection scheme is based on the 2nd order Runge Kutta method. Lagrangian trajectories are obtained from the vertical displacement induced by advection (i.e. vertical current and vertical larval behavior) and a non-naive random walk based on the vertical profile of turbulent diffusion. The method relies on the studies of Visser (1997) and improved later on by North (2006) in order to account properly for sharp vertical structure of the vertical mixing that may be encountered in stratified medium such as the Seine plume.

\subsubsection{Biological submodel}

Spawning behaviour was introduced in the model to mimic field observations on the scallop reproduction. For bay of Saint-Brieuc, there are two spawning dates: the first one on the day on which simulated sea surface temperature exceeded $16^{\circ} \mathrm{C}$ and the second one three weeks later (Paulet and Fifas 1989; Paulet et al. 1992). For the bay of Seine, a first spawning episode occurs for a sea surface temperature of $16^{\circ} \mathrm{C}$ and afterwards there are multiple spawning events every 8 days until the end of August (Lubet et al. 1987). The number of spawning events for this bay varies between 6 and 10 depending on the date of the first spawning. 
The relationship between the planktonic larval duration (PLD in days) of scallop and the temperature $\left(\mathrm{T}\right.$ in ${ }^{\circ} \mathrm{C}$ ) was determined from a review of the different laboratory experiments performed on Pecten larval development at different temperature ranging from 9 to $20^{\circ} \mathrm{C}$ (Comely 1972 ; Gruffydd and Beaumont 1972; Sasaki 1979; Paulet et al. 1988; Beaumont and Barnes 1992; Robert and Gérard 1999). The following equation was obtained: PLD $=-4.277 \mathrm{~T}+102.01(\mathrm{n}$ (observation number $)=11 ; \mathrm{R}^{2}$ (determination coefficient $)=0.8467 ; \mathrm{p}$-value $\left.<0.05\right)$. Estimation of the PLD in relation with the spatial and temporal variation in temperature was simulated as proposed by Dawirs (1985). First, the PLD was calculated for a given date of larval release from the previous equation assuming that water temperature remains constant. During the following day, the daily development rate is $1 / \mathrm{PLD}$ which corresponds to the proportion of the total development. If one day after spawning, water temperature encountered by larvae becomes either warmer or cooler, the estimated PLD will be slightly shorter or longer. The real PLD of each larva on the basis of varying daily field temperature is then calculated by adding the reciprocal values of the PLD in different subsequent daily mean water temperatures. The total PLD equals the number of days once this summation reaches zero.

Larval behaviour was parameterized in the model from laboratory experiments performed by Cragg (1980). Although Cragg reported initially the ontogenic changes in larval behaviour according to the larval age, from the gastrula stage to the 40 days old pediveliger stage, we defined in our study variations in larval behaviour according to the fraction of the total larval development to take into account the variations in PLD due to temperature. During the first $6.6 \%$ of larval development, gastrula and trocophore larvae are either unable to propel themselves or swim continuously in an erratic manner so that we consider that these stages act as neutrally buoyant particles. Later, veliger larvae swim up a vertically orientated path and intermittently stop swimming by retracting the velum and closing the shell valves. From $6.6 \%$ to $82 \%$ of larval development, the instantaneous linear swimming speed linearly increases from 0.5 to $1.2 \mathrm{~mm} \mathrm{~s}^{-1}$ while it linearly decreases from 1.2 to 0.4 $\mathrm{mm} \mathrm{s}^{-1}$ for the rest of larval development. As the speed of sinking larvae after the retraction of the velum is greater than that of actively swimming larvae for Pecten maximus (Cragg 1980) as well as for most bivalve larvae (Wang and Xu 1997), we assume that the sinking speed linearly increases from 0.6 to $2 \mathrm{~mm} \mathrm{~s}^{-1}$. The value of $0.6 \mathrm{~mm} \mathrm{~s}^{-1}$ was closed to sinking speed reported for early veliger of 
different bivalve species (Mann et al. 1991; Wang and Xu 1997) while the value of $2 \mathrm{~mm} \mathrm{~s}^{-1}$ was measured for young spat of Pecten maximus (Beaumont and Barnes 1992). If the percent time spent swimming is unknown for scallop larvae, it varies between a maximum of $83 \%$ and a minimum of $64 \%$ in response to vertical salinity changes for another bivalve, the oyster Crassostrea virginica (Dekshenieks et al. 1996). It was then fixed to $75 \%$ in our study. At the end of the larval phase, the pediveliger stage remains close to the bottom and search for a substrate suitable for settlement by crawling on or swimming just above the bottom (Cragg 1980). Due to the lack of knowledge on the physical, chemical and biological features which govern this bottom searching phase, this behaviour which may influence larval distribution at a scale below the model mesh size was not simulated.

\subsubsection{Numerical experiments}

For each simulation, 3000 particles evenly distributed in the water column were released in the different subareas of each bay. This choice of 3000 particles is a trade off between realistic dispersal scheme and realistic time of simulation. The comparison between Eulerian and Lagrangian simulations of larval dispersal after 34 days for spawning dates of 8 August 2000 for the bay of SaintBrieuc (Fig. 3a) and on 19 August 2001 for the bay of Seine (Fig. 3b) validates this choice The dispersal schemes (i.e. main axes of larval dispersal and spatial gradients in larval distribution) are similar. Moreover, the mean concentration in each bay is very close between the Lagrangian and the Eulerian experiments (Fig. $3 \mathrm{c}$ and f). At the scale of spawning areas examined, Eulerian and Lagrangian are very close: the higher difference of concentration doesn't reach 0.05 micromole/L and the maximum and minimum concentrations are observed for the same areas in the two cases (Fig.3 c and f). By contrast, Lagrangian simulations favour the readability of extreme dispersal events, for example in the North of the Cotentin Peninsula for a larval release in the bay of Saint-Brieuc, or in the south of the Saint-Malo gulf for a larval release in the bay of Seine. So, this is one reason to choose the Lagrangian approach. The second is the possibility with Lagrangian simulation to use centred individual model that is impossible with Eulerian approach.

We run the model for 10 years (i.e. 2000 to 2009) to account for a set of various tidal and meteorological situations and describe the interannual variability in larval dispersal. The beginning of 
each simulation was the spawning dates determined from the simulated SST for each bay. Larvae were released following discrete events. A first set of experiments was achieved assuming a passive transport (PT) and a constant planktonic larval duration of 34 days (i.e. PLD for a temperature of $16^{\circ} \mathrm{C}$ on average within the bay according to the relationship established between the PLD and the temperature). This first set was conducted to determine the role of the hydrodynamic variability on the variations of larval dispersal and is used later as the baseline to test the role of biological factors. In a second set of experiments, variations of the PLD according to the temperatures encountered by larvae over time and space have been considered. Finally, in a third type of experiments, we took into account the swimming behaviour (SB) of Pecten larvae with a temperature dependent PLD.

\subsection{Dispersal kernel descriptors}

At the end of the larval dispersal phase, the number of particles retained in the different subareas of each bay was calculated. These larvae were considered as successful settlers regardless of their height above the bottom and the quality of the substrate. The end of the dispersal phase is either fixed for all larvae (i.e. first set of experiments) or variable among larvae (i.e. first and second sets of experiments).

The dispersal kernel is defined as the density of settling particles which originate from a given location normalized by the number of particles released in a 1 or $2 \mathrm{D}$ space. To analyse the dispersal schemes resulting from our experiments, we have retained two parameters describing 2D dispersal kernels following Edwards et al. (2007): the mean distance dispersed (D) and the isotropy of the larval population (I). The isotropy depends on the overall inertia which characterises the variance of larval distribution around the mean geographic position of larvae. Inertia can be decomposed into two orthogonal axes representing the maximum (Imax) and the minimum (Imin) parts of the overall inertia. These parameters were calculated by a principal component analysis performed on the ending positions of larvae. Isotropy is then defined by the square root of ratio between Imax and Imin $\left(\sqrt{\frac{\text { Imin }}{\operatorname{Imax}}}\right)$. Those parameters are used to quantify the impact of biological processes such as temperature dependent PLD and swimming behaviour on dispersal pattern. 


\section{Results and discussion}

\subsection{Model validation}

The reproductive behaviour of Pecten as well as the planktonic larval duration were strongly dependent on temperature so that the model must be very accurate for predictions of sea surface temperature (SST). For example, a bias of $1{ }^{\circ} \mathrm{C}$ for temperature generates an error exceeding 4 days for PLD which corresponds to an error exceeding $10 \%$ in comparison with a constant PLD of 34 days. After a control of the accuracy of the simulated instantaneous currents by the model as reported by Lazure and Dumas (2008) (data not shown), the effort of model parameterization has been made to reduce the bias of temperature as much as possible. This effort concerns the parameterization of viscosity, wind drag coefficient, relaxation of boundary conditions and turbulence scheme. The map of mean error for SST calculated for June, July and August 2005 and 2006 shows that the differences between the observations and the model do not exceed $1^{\circ} \mathrm{C}$ (Fig. 4a). The temporal evolution of mean error (Fig.4b) shows that there are only a few peak reaching 2 degrees. Most of errors are smaller than 1 degree. Although the SST error is maximal in nearshore waters, it is lower than $0.4^{\circ} \mathrm{C}$ in the bay of Saint-Brieuc and the bay of Seine; such error leads to a PLD error lower than 1.6 days and can be considered insignificant. Consequently, the model outputs can be considered sufficiently realistic to be used in this Lagrangian transport study.

\subsection{Experiment 1: passive transport}

The first experiment of Lagrangian transport shows different levels of intra- and interannual variability of dispersal pattern from 2000 to 2009 between the bay of Saint-Brieuc and the bay of Seine.

The results of larval distribution after 34 days of dispersal in the bay of Saint-Brieuc show the same dispersal scheme whatever the spawning dates with two major axes of transport: one transport axis towards the North at the periphery of the Saint-Malo Gulf for larvae released in the subareas 1 to 4 or 5, and one towards the East and then the North along the coast of the Cotentin Peninsula for larvae released in the subareas 5 and 6 (Fig. 5). Only, the extent of larval dispersal presents some differences within and between years in response to the variability of wind direction and velocity as 
shown for the different spawning dates in 2000 and 2001. Thus, the larvae for a spawning date on 8 August 2000 (Fig. 5 b) are more dispersed to the North than for a spawning date on 18 July 2000 (Fig. 5a). For a spawning date on 18 July 2000, the moderate northern wind which blew during most of the planktonic larval life span tended to retain larvae in the bay. Conversely, for a spawning date on 8 August 2000, the wind was mainly from the south-west and promoted larval export in offshore waters to the north. On the other hand, the larvae for spawning episodes of 2001 (Fig. 5c and d) are in general less dispersed than for spawning episodes of 2000 (Fig. 5a and b). Again, the variability in meteorological conditions can explain the simulated larval distribution. For the spawning date on 24 July 2001, the dispersal scheme is very similar to this obtained on 8 August 2000 in similar wind conditions. For the spawning date on 3 July 2001, there is no or little wind during the 10 first days of dispersal and then a western wind which favours a strong larval retention within the bay for larvae released in subareas 1 to 4 but an intense transport along the coasts of the Cotentin Peninsula for larvae released in the subareas 5 and 6. Depending on the wind regime, larvae from the subareas 5 are either transported to the North or to the East. Whatever the spawning dates, the larvae remain in the western English Channel and never pass off the Cotentin head. The stability in the pattern of larval dispersal in the bay of Saint-Brieuc is due to the major role of the tidal residual circulation in this area which constrains the water mass transport (Salomon and Breton 1993).

Whatever the direction or the amplitude of wind, the intense tidal residual gyres which develop in the Normand-Breton gulf around the Channel Isles persist and constrain the water mass transport outside the gyres, either toward the North at the periphery of the gulf, or along a coastal band to the East (Salomon and Breton 1993). These "around islands" gyres may then act as slings projecting larvae outwards (Ménesguen and Gohin 2006). At a smaller scale, most larvae are transported from the east to the west of the bay of Saint-Brieuc as expected from the fields of tidal residual currents which follow the isobaths (Thouzeau and Lehay 1988). Only larvae released from the subarea 6 exhibit different larval trajectories. This latter result highlights the role of spawning location on the pattern of larval dispersal in relation to the spatial variability in the structure of flows in nearshore waters (Largier 2003; Ayata et al. 2009). 
According to these schemes of dispersal patterns, the mean percentage of larvae retained within the bay of Saint-Brieuc after 34 days identifies two different spawning sectors within the bay (Fig. 6). The larvae from subareas 1, 2 and 3 in the western part of the bay are less retained in the bay (i.e. retention rate $<36 \%$ ) due to an offshore export than larvae from subareas 4,5 and 6 in the eastern part of the bay (i.e. retention rate $>75 \%$ ) (Fig. 6a). Larvae from subareas 4, 5 and 6 are mainly transported to the west and settled preferentially in subareas 1, 2 and 3 (Fig. 6b, c, d). It is worth noting with respect to the resource management that this sector appears then as the main source of larvae for the Pecten maximus population in the bay of Saint-Brieuc. The analysis of settlers' distribution in the bay of Saint-Brieuc in fall 1985 suggested also that larval supply was most important in the western part of the bay (Thouzeau and Lehay 1988). If we weight the mean percentage of larvae retained in each area by the relative importance of each area for the stock (fig. 6d), only the subareas 5 and 6 are the most important areas for the stock management. These subareas which formed $34 \%$ of the Pecten stock for the period 1990-1999 contribute to more than $51 \%$ of the total settlement. This result is even more important considering the recent spreading of the invasive gastropod Crepidula fornicata and the subsequent shift in Pecten maximus distribution in the bay (Hamon and Blanchard 1994). For the period 2000-2009, the subareas 5 and 6 formed then $42 \%$ of the adult stock and $59 \%$ of the larval supply within the bay.

The results of larval distribution after 34 days of transport in the bay of Seine show a stronger intra-and inter-annual variability of dispersal so that even larvae resulting from 2 spawning dates only separated by 8 days may have a totally different dispersal scheme (Fig. 7). The variability in larval dispersal is mainly due to complex interactions between the wind-induced circulation and the tidal residual circulation, and is more or less important depending on the location of the spawning release area. For example, most larvae from the subarea 5 (North-eastern subarea of the bay) either stay in the bay of Seine, as reported for spawning dates on 17 July 2000, on 28 June 2003 and 8 July 2006, (Fig. 7a, $\mathrm{c}$ and d), or are transported to the eastern English Channel as shown for a spawning date on 25 July 2000 (Fig. 7b). For the spawning dates on 17 July 2000 and 28 June 2003, the wind was mainly from the north-east during the first part of the larval life span, promoting larval retention into the bay, and then turned to the west or the south-west while the wind was mostly to the west for the spawning date 
on 25 July 2000, then transporting larvae towards the east. The comparison between the two spawning dates in July 2000 which were only 8 days apart suggests that processes which control larval transport at the beginning of the dispersal may be essential for the rest of the larval dispersal and that larval supply to benthic populations may be determined early in the larval life. The larvae from the subareas 1,2 and 3 are mainly transported to the west and then to the north where they are trapped within a gyre off Barfleur which has been classified as a retention area for particles (Ménesguen and Gohin 2006). Nevertheless, some of these larvae may reach the Channel Islands; that is the case for all spawning dates although the magnitude of this transport is highly variable (Fig. 7). Larvae from the subarea 4 remain mainly within the bay of Seine but are either transported to the west (e.g. spawning date on 17 July 2000) or to the east (e.g. spawning date on 28 June 2003) depending on the wind regime. Small gyres described along the southern coasts of the bay of Seine may also favour local larval retention. The gyres in the south of the bay of Seine and off Barfleur are quite sensitive to the wind and disappear when the wind velocity exceeds 7-8 $\mathrm{m} \mathrm{s}^{-1}$ (Salomon and Breton 1993). By disrupting the gyres, a short event of strong wind may be sufficient to alter larval retention and favour a transport to the west or to the east. For a spawning date on 28 June 2003, the wind is northward pushing the larvae out of the bay of Seine and after it shifts south-westward and transports the dispersal cloud towards Channel Islands. Our observations are in good agreement with previous works on the dispersal of dissolved elements or larvae. Bailly du Bois and Dumas (2005) have shown that the becoming of radionuclides released at La Hague is strongly dependent to the wind regime: for southerly and westerly forcing, the entire release is carried in the Channel flux towards the North Sea. For northerly or easterly forcing, a significant portion of release is directed towards the gulf of Saint-Malo and dispersed within the gyres along the Channel Islands. Likewise, different authors highlighted the role of transitory events due to wind conditions on the variability in larval dispersal in the eastern English Channel from field studies (Thiébaut et al. 1998) or from modelling studies (Ellien et al. 2004; Jolly et al. 2009).

Despite a variable transport, the mean percentage of larvae retained in the bay of Seine after 34 days was high with values often higher than $50 \%$ whatever the considered subarea (Fig. 8a). The minimum retention rate was observed for the subarea 5 due to the export of larvae from this subarea to 
the eastern English Channel two once on average according to our simulations. Consequently, adult Pecten from this subarea can be a source of larvae for the scallop populations located in the eastern English Channel. The high variability in the pattern of larval dispersal from the subarea 5 could then explain the high inter-annual variability in the scallop stocks observed for the eastern English Channel (Vigneau 1994). On the other hand, a few larvae from the subareas 1, 2 and 3 can colonize small scallop populations located around the Channel Islands. Larval retention was also less variable among the different spawning subareas in comparison with the previous results in the bay of Saint-Brieuc. However, because of a large heterogeneity in the distribution of the scallop stock in the bay of Seine with the subareas 2 and 3 harbouring more than $60 \%$ of adults, these two zones contribute to more than $68 \%$ of the total number of settlers in the bay (Fig. $8 b$ ).

The comparison of larval dispersal in the bay of Saint-Brieuc and the bay of Seine indicates two different patterns: one where the tidal residual currents play a major role to determine the main directions of the dispersal so that intra- and inter-annual variability is low and one where the role of wind-induced currents is more significant and temporal variability is higher. In both bays, the spatial heterogeneity in larval supply depends on the spatial variability in local hydrodynamics but also on the spatial variability in the quality of the habitat and consequently the reproductive output. Although this biological parameter is rarely considered in the study on larval dispersal and connectivity (but see Treml et al. 2012), it is determinant to identify the major local sources of larvae for each bay in the context of a spatial management of fisheries.

\subsection{Experiment 2: Temperature dependent PLD}

The second numerical experiment consists in adding a variable PLD linked to temperature encountered by larvae. The PLD is then often shorter than 34 days and varies over time, i.e. between the different larval releases during the reproductive period, but also over space, i.e. between the different subareas (Fig. 9). For the bay of Saint-Brieuc, the maximum mean PLD is 37 days for a larval release in the subarea 1 for the first spawning event while the minimum mean is 25 days for a larval release in the subarea 6 for the second spawning event. For each spawning event, the mean PLD decreases from the west to the east according to the horizontal gradients of temperature. Larvae from 
the subareas 4, 5 and 6 remain in the coastal and warmers waters of the bay and have consequently a shorter PLD than larvae from the subareas 1, 2 and 3 which are mainly exported in offshore and cooler waters. For the bay of Seine, the mean PLD varies between 23 and 34 days. The temporal variability in the PLD is more pronounced due to the protracted reproductive period from June to August.

The integration of a temperature dependent PLD in the model provides the same results for the two bays. Although the general patterns in larval dispersal are identical to the previously described experiment, the main effect of taking into account a variable planktonic larval duration is a decreasing in the mean distance dispersed (D) (Table 1) and the maximal extent of the larval population (Figs. 10 and 11). This effect is even more pronounced for the bay of Seine where the mean dispersed distance is lower by $13 \mathrm{Km}$ (i.e. $23 \%$ of the transport of passive larvae). Moreover, it also increases the retention in the bay of Saint-Brieuc and in the bay of Seine for 10 and $7 \%$ respectively without modifying notably the relative importance of each subarea on larval supply (Fig. 12).

The effect of temperature dependent PLD has been also showed to play a major role for Placopecten magellanicus larval dispersal on Georges Bank so that a change in mean PLD of a few days can greatly alter connectivity (Gilbert et al. 2010). On the other hand, by controlling the duration of exposure to different sources of larval mortality (e.g. predation), temperature may affect the larval survival which generally decreases exponentially with time (O'Connor et al. 2007). If we assume that the larval mortality rate is not affected by the range of temperature encountered by larvae in the present study (i.e. 15 to $20{ }^{\circ} \mathrm{C}$ ), the larval survival rate and consequently larval supply will also increase in warmer waters and strengthen the effect of temperature on the scallop dispersal depicted in the present study.

\subsection{Experiment 3: effect of swimming}

While passive larvae are evenly distributed over the water column (Fig. 13 a), the main effect of the swimming behaviour is to differently locate larvae in water column during their ontogenic development (Fig. 13b). With swimming behaviour, young larvae are mainly concentrated in the surface waters in the first 5 meters. After 15 days, they have begun to be more evenly distributed in the water column as the difference between the swimming velocity and the sinking velocity increased. 
Finally, they tended to be located near the bottom at the end of transport phase. Qualitatively, this general pattern is in agreement with the ontogenic changes in the vertical distribution of larvae expected from laboratory experiments (Cragg 1980). Unfortunately, the lack of field observations on larval distribution prevents any validation of the biological submodel.

The comparison between larval dispersal after 34 days of passive transport (left), after a passive transport with a variable PLD (middle) and after an active transport with a variable PLD (right) for different spawning dates are shown on Figs. 10 and 11 for the bay of Saint-Brieuc and the bay of Seine. The dispersal scheme in terms of transport axis and maximal larval dispersal does not really differ when swimming behaviour is taking into account in most cases. An exception is noted for a spawning date on 7 August 2007 in the bay of Seine: the cloud of larvae from the subarea 5, close to the Seine estuary, remains manly located above the larval release area for passive particles while active larvae are mainly transported to the north-east. Another effect of the swimming behaviour is a mean decrease of the PLD by about 1 day (average on all simulations) which can be related to small vertical gradients in temperature in some areas like the eastern bay of Seine (Cugier and Le Hir 2002). This result suggests then that two different biological factors (i.e. a temperature dependent PLD and swimming behaviour) may interact in the control of larval dispersal. An active behaviour modifies then the parameters of the dispersal kernel (Table1 a and b). Depending on the subarea, the mean dispersed distance (D) is either increased or decreased by a few $\mathrm{km}$. By contrast, the isotropy (I) is always higher when the swimming behaviour is taking into account whatever the subareas in the bay of Saint-Brieuc or the bay of Seine. Consequently, larval horizontal dispersion tends to increase for active larvae. This result differs from a previous study in the Bay of Biscay which showed that vertical larval behaviour mainly decreased the size of the variance ellipses by reducing inter-individual variability in the larval trajectories (Ayata et al. 2010). The differences of dispersal kernel after 5 days (table $1 \mathrm{c}$ and $\mathrm{d}$ ) between passive transport and active behaviour show that with swimming, the mean distance is always higher and the isotropy is smaller. It is due to the fact that, at the beginning, the swimming speed of larvae is higher than sinking speed so larvae are concentrated near the surface: they can be transported further thanks to wind training (higher D) and they remain all together (smaller I). After, the swimming speed is equilibrated with sinking speed so the differences fade. 
Our results highlight a minor role of larval behaviour contradicting different recent studies on the modelling of bivalve larvae dispersal. For example, North et al. (2008) have demonstrated that even simple differences in larval swimming behaviours of two oysters species (Crassostrea virginica and $C$. ariakensis) in response to salinity gradients could have significant consequences for dispersalrelated processes in Chesapeake Bay (i.e. dispersal distances, transport success and the connectivity between subpopulations. On Georges Bank, the aggregation of Placopecten magellanicus larvae at the pycnocline in stratified regions seem to improve modelled distribution of larvae in some parts of the study area in comparison with results for passive particles (Gilbert et al. 2010). Although the influence of larval behaviour on dispersal varies spatially, its effects on larval retention and connectivity between subpopulations are comparable to the modelled effects of variability in the circulation. We cannot exclude in our study that the idealized simulated behaviour does not reflect the complex behaviour of scallop larvae and consequently influence our results. For example, Kaartvedt et al. (1987) suggested from mesocosms observations that Pecten larvae may respond to light changes and exhibit a diel vertical migration. However, the role of larval behaviour on larval dispersal has been mainly reported in stratified areas where baroclinic flows are important and where vertical changes in the velocity and direction of the current are significant. In the English Channel where currents are mainly barotropic, the influence of larval behaviour is probably limited to the western entrance of the Channel where the water column is seasonally stratified, in the eastern bay of Seine and in small coastal embayments receiving significant freshwater inputs. In Poole Harbour (south England), the retention of the non-indigeneous Manila clam Ruditapes philippinarum is considerably affected by variations in the behavioural response of larvae to salinity (Herbert et al. 2011).

\section{Summary / conclusion}

The present study focused on the Lagrangian transport of scallop larvae in the bay of SaintBrieuc and the bay of Seine from 2000 to 2009. The results of MARS-3D model show that larval transport in these two bays is strongly linked to the tidal residual circulation and the wind induced currents. This latter hydrodynamical factor is the main source of variability in the extent of larval dispersal and the local retention rate. The main effect of a variable PLD dependent on temperature is 
to reduce the spread of dispersal and consequently increase by about $10 \%$ the local retention and the larval supply. By contrast, the swimming behaviour does not fundamentally change the dispersal scheme except in the eastern bay of Seine. Even if the PLD is decreased by 1 day with swimming behaviour, the mean distance $\mathrm{D}$ is inceased by $2 \mathrm{Km}$ in these areas. Within each bay, our results allow to describe the connectivity between subpopulations and to identify the main sources of larvae which depend on both the characteristics of local hydrodynamics and the heterogeneity in the reproductive outputs. For the bay of Saint-Brieuc, the eastern subpopulations of Pecten maximus are the main sources of larval for the whole bay. For the bay of Seine, central subpopulations are the most important sectors for the local stock while the northeastern subpopulation is probably one source of larvae for populations in the eastern English Channel.

Our study was aiming to understand the impact of hydrodynamics and only two biological parameters (i.e. temperature dependent PLD and swimming behaviour) assumed to be the most important on the dispersal of scallop larvae. So, it is important to keep in mind the limitations of this numerical study to depict exhaustively larval dispersal. For example, we do not have taken in consideration the presence of food for parameterisation of PLD or swimming behaviour. The mortality is non-existent. It is the first step of a larger study on connectivity between all stocks of king scallop in the English Channel. It has permitted to show that the temperature dependent PLD is necessary to have a good representation of dispersal and then large scale connectivity. On the contrary, the swimming behaviour seems to be a minor factor (compared with effect of PLD) except in some areas that may be neglected in a first approximation.

\section{Acknowledgements}

This research was supported by the ANR project COMANCHE (ANR-2010-STRA-010-02).

The authors acknowledge the anonymous reviewers for the helpful and constructive comments. 


\section{References}

Ayata SD, Ellien C, Dumas F, Dubois S and Thiébaut E (2009) Modelling larval dispersal and settlement of the reef-building polychaete Sabellaria alveolata: role of hydrodynamic processes on the sustainability of biogenic reefs. Cont. Shelf Res. 29: 1605-1623

Ayata SD, Lazure P and Thiébaut E (2010) How does the connectivity between populations mediate range limits of marine invertebrates? A case study of larval dispersal between the Bay of Biscay and the English Channel (North-East Atlantic). Prog. in oceanogr. 87: 18-36

Bailly du Bois P and Dumas F (2005) Fast hydrodynamic model for medium- and long-term dispersion in seawater in the English Channel and southern North Sea, qualitative and quantitative validation by radionuclide tracers. Ocean Modelling 9: 169-210

Beaumont AR and Barnes DA (1992) Aspects of veliger larval growth and byssus drifting of the spat of Pecten maximus and Aequipecten (Chlamys) opercularis. ICES J. Mar. Sci. 49: 417-423

Blanchard M (1997) Spead of the slipper limpet (Crepidula fornicata) in Europe. Current state and consequences. Sci. Mar. 61: 109-118

Brand AR (2006) Scallop Ecology: distribution and behaviour, in: Developments in aquaculture and fisheries science, vol. 35: Scallops: Biology, ecology and aquaculture, Ed. Shumway and Parsons, pp $651-744$

Chauvaud L, Thouzeau G and Paulet YM (1998) Effects of environmental factors on the daily growth rate of Pecten maximus juveniles in the bay of Brest (France). J. Exp. Mar. Biol. and Ecol. 227: 83111 
Chia FS, Buckland-Nicks J, Young CM (1984) Locomotion of marine invertebrate larvae: a review. Can. J. Zool. 62: 1205-1222

Comely CA (1972) Larval culture of the scallop Pecten maximus (L.). J. Cons. Int. Explor. Mer. 34: $365-378$

Cowen R.K. and Sponaugle S. (2009) Larval dispersal and marine population connectivity. Ann. Rev. Mar. Sci. 1: 443-466

Cragg SM (1980) Swimming behaviour of the larvae of Pecten maximus (L.) (Bivalta). J. Mar. Biol. 60: $551-564$

Cragg SM (2006) Development, physiology, behaviour and ecology of scallop larvae, in: Developments in aquaculture and fisheries science, vol. 35: Scallops: Biology, ecology and aquaculture, Ed. Shumway and Parsons, pp 45-122

Cugier P and Le Hir P. (2002) Development of a 3D hydrodynamic model for coastal ecosystem modelling. Application to the plume of the Seine River (France). Est. Coast. And Shelf Sci. 55(5): $673-695$

Dawirs R (1985) Temperature and larval development of Carcinarus maenas (Decapoda) in the laboratory: predictions of larval dynamics. Mar. Ecol. Prog. Ser. 24: 297-302

Dekshenieks MM, Hofmann EE, Klinck JM and Powell EN (1996) Modeling the vertical distribution of oyster larvae in response to environmental conditions. Mar. Ecol. Prog. Ser. 136: 97-110 
Edwards KP, Hare JA, Werner FE and Seim H (2007) Using 2-dimensional dispersal kernels to identify the dominant influences on larval dispersal on continental shelves. Mar. Ecol. Prog. Ser. 352: $77-87$

Ellien C, Thiébaut E, Dumas F, Salomon JC, Nival P (2004) A modelling study of the respective role of hydrodynamic processes and larval mortality on larval dispersal and recruitment of benthic invertebrates : example of Pectinaria koreni (Annelida: Polychaeta) in the bay of Seine (English Channel). J. Plank. Res. $26: 117-132$

Fifas S (1993) Analyse et modélisation des paramètres d'exploitation du stock de coquilles saintjacques (Pecten maximus L.) en baie de Saint-Brieuc (Manche ouest, France). Thesis 428 pp (http://archimer.ifremer.fr/doc/1993/rapport-1518.pdf)

Fifas S (2004) la coquille Saint Jacques en Bretagne, rapport ifremer, 14 pp. (http://envlit.ifremer.fr/content/download/64839/461476/version/1/file/20041207Coquille_Saint_Jacq ues_Bretagne.pdf)

Fogarty MJ and Botsford LW (2007) Population connectivity and spatial management of marine fisheries. Oceanography 20(3): 112-123

Gilbert CS, Gentleman WC, Johnson CL, DiBacco C, Pringle JM and Chen C (2010) Modelling dispersal of sea scallop (Placopecten magellanicus) larvae on Georges Bank: the influence of depthdistribution, planktonic duration and spawning seasonality. Prog. Oceanogr. 87: 37-48

Gruffydd LD and Beaumont AR (1972) A method of rearing Pecten maximus larvae in the laboratory. Mar. Biol. 15: 350-355 
Guitton J, Dintheer C, Dunn MR, Morizur Y and Tetard A (2003) Atlas des pêcheries de Manche. Ed. Ifremer, $216 \mathrm{pp}$

Hamon D and Blanchard M (1994) Etat de la prolifération de la crépidule (Crepidula fornicata) en baie de Saint-Brieuc. Rapport Ifremer, DEL 94-14, 29 pp

Herbert RJH, Willis J, Jones E, Ross K, Hübner R, Humphreys J, Jensen A and Baugh J (2011) Invasion in tidal zones on complex coastlines: modeling larvae of the non-native Manila clam, Ruditapes philippinarum, in the UK. J. Biogeogr. 39: 585-599

Huret M, Petitgas P and Woillez M (2010) Dispernal kernels and their drivers captured with a hydrodynamic model and spatial indices: a case study on anchovy (Engraulis encrasicolus) early life stages in the Bay of Biscay. Prog. in Oceanogr. 87: 6-17

Jolly MT, Guyard P, Ellien C, Gentil F, Viard F, Thiébaut E and Jolivet D (2009) Population genetics and hydrodynamic modelling of larval dispersal dissociate contemporary patterns of connectivity from historical expansion into European shelf seas in the polychaete Pectinaria koreni (Malmgren). Limn. And Oceanogr. 54: 2089-2106

Kaarvedt S, Aksnes DL and Egge JK (1987) Effect of light on the vertical distribution of Pecten maximus larvae. Mar. Ecol. Prog. Ser. 40: 195-197

Largier JL (2003) Considerations in estimating larval dispersal distances from oceanographic data. Ecol. App. 13(1): S71-S89

Lazure P and Dumas F (2008) An external-internal mode coupling for a 3D hydrodynamical model for applications at regional scale (MARS). Adv. Water Resour. 31: 233-250 
Lazure P, Garnier V, Dumas F, Herry C and Chifflet M (2009) Development of a hydrodynamic model of the Bay of Biscay. Validation of hydrology. Cont. Shelf Res. 29: 985-997

Le Boyer A, Cambon G, Daniault N, Herbette S, Le Cann B and Marié L (2009) Observations of the Ushant tidal front in September 2007. Cont. Shelf Res. 29: 1026-1037

Le Pennec M, Paugam A and Le Pennec G (2003) The pelagic life of the pectinid Pecten maximus - a review. ICES J. Mar. Sci. 60: 211-223

Levin LA (2006) Recent Progress in understanding Larval Dispersal: New Directions and Disgressions. Int. and Comp. Biol. 46 : 282-297

Lubet P, Besnard J, Faveris R and Robbins I (1987) Physiologie de la reproduction de la coquille Saint Jacques (Pecten maximus L). Oceanis 13: 265-290

Lyard F, Lefevre F, Letellier T and Francis O (2006) Modelling the global ocean tides: modern insights from fes2004. Ocean Dyn. 56: 394-415

Mann R, Campos BM and Luckenbach MW (1991) Swimming rate and responses of larvae of three mactrid bivalves to salinity discontinuities. Mar. Ecol. Prog. Ser. 68: 257-269

Ménesguen A and Gohin F (2006) Observation and modeling of natural retention structures in the English Channel. J. Mar. Syst. 63: 244-256

Miller TJ (2007) Contribution of individual-based coupled physical-biological models to understanding recruitment in marine fish populations. Mar. Ecol. Prog. Ser. 347: 127-138 
Nicolle A, Garreau P and Liorzou B (2009) Modelling for anchovy recruitment studies in the Gulf of Lion (Western Mediterranean Sea). Ocean Dynamics 59(6): 953-968

North EW, Hood RR, Chao SY and Sanford LP (2006) Using a random displacement model to simulate turbulent particle motion in a baroclinic frontal zone: a new implementation scheme and model performance tests. J. Mar. Syst. 63: 365-380

North EW, Schlag Z, Hood RR, Li M, Zhong L, Gross T and Kennedy VS (2008) Vertical swimming behavior influences dispersal of simulated oyster larvae in a coupled particle-tracking and hydrodynamic model of Chesapeake Bay. Mar. Ecol. Prog. Ser. 359: 99-115

O'Connor MI, Bruno JF, Gaines SD, Halpern BS, Lester SE, Kinlan BP and Weiss JM (2007) Temperature control of larval dispersal and the implications for marine ecology, evolution, and conservation. PNAS 104: 1266-1271

Palumbi SR (2004) Marine Reserves and Ocean Neighborhoods: The Spatial Scale of Marine Populations and Their Management. Ann. Rev. of Env. Res. 29: 31-68

Paugam A, Le Pennec M, Marhic A and Andre-Fontaine G (2003) Immunological in situ : determination of Pecten maximus larvae and their temporal distribution. J. Mar. Biol. Assoc. UK. 83: $1083-1093$

Paulet YM and Fifas S (1989) Etude de la fécondité potentielle de la coquille Saint-Jacques Pecten maximus, en baie de Saint-Brieuc. Haliotis 19: 275-285

Paulet YM, Lucas A and Gérard A (1988) Reproduction and larval development in two Pecten maximus (L.) population from Brittany. J. Expl. Mar. Biol. Ecol. 119 : 145-156 
Paulet YM, Ôorange G, Cochard IC and Le Pennec M (1992) Reproduction et recrutement chez Pecten maximus L.Ann. Inst. océanogr., Paris, 68(1-2): 45-64

Pingree RD (1980) Physical oceanography of the Celtic Sea and English Channel. In: The North-west European shelf sea: Sea Bed and the Sea in Motion II. Phys and chem Oceanogr and Phys Res. Elsevier Oceanography Series, 638pp

Quéro JC and Vayne JJ (1998) Les fruits de la mer et plantes marines des pêches françaises. Ifremer, Delachaux and Niestlé (Ed.), 256pp

Robert R and Gérard A (1999) Bivalve hatchery technology: the current situation for the Pacific oyster Crassostrea gigas and the scallop Pecten maximus in France. Aq. Liv. Res. 12(2): 121-130

Salomon JC and Breton M (1993) An atlas of long-term currents in the Channel, Oceanologica Acta 16(5-6): 439-448

Sasaki R (1979) A report on study of scallop and oyster in the course of Japan/Scotland exchange research scholarship 1977/78. Published by Fisheries Division, Highlands and Islands Dev. Board, Scotland, $24 \mathrm{pp}$

Shanks AL, Grantham BA and Carr MH (2003) Propagule dispersal distance and the size and spacing of marine reserves. Ecol. App. 13: 159-169

Smagorinsky J (1963) General circulation experiments with the primitive equation. I. The basic experiment. Mon. Weather Rev. 111: 99-165 
Thiébaut E, Lagadeuc Y, Olivier F, Dauvin JC and Retière C (1998) Do hydrodynamic factors affect the recruitment of marine invertebrates in a macrotidal area? The case study of Pectinaria koreni (Polychaeta) in the Bay of Seine (English Channel). Hydrobiol. 375/376: 165-176

Thouzeau G and Lehay D (1988) Variabilité spatio-temporelle de la distribution, de la croissance et de la survie des juvéniles de Pecten maximus (L.) issus des pontes 1985, en baie de Saint-Brieuc. Oceanol. Acta 11: 267-284

Thouzeau G, Chauvaud L, Grall J and Guérin L (2000) Rôle des interactions biotiques sur le devenir du pré-recrutement et la croissance de Pecten maximus (L.) en rade de Brest. C. R. Acad. Sci. Paris, Sciences de la vie/Life sciences $323: 815-825$

Treml EA, Roberts JJ, Chao Y, Halpin PN, Possingham HP and Riginos C (2012) Reproductive output and duration of the pelagic larval stage determine seascape-wide connectivity of marine populations. Int. and Comp. Biol. 52: 525-537

Velo-Suarez L, Reguera B, Gonzales-Gil S, Lunven M, Lazure P, Nézan E and Gentien P (2010) Application of a 3D Lagrangian model to explain the decline of a Dynophysis acuminate bloom in the Bay of Biscay. J. Mar. Syst. 83: 242-252

Vignaud J (1994) Evaluation du stock de coquilles Saint Jacques de la Manche Est. Rapport Ifremer, 30pp (http://archimer.ifremer.fr/doc/00076/18752/16323.pdf)

Vignaud J, Fifas S and Foucher E (2001) Les campagnes d'évaluation du stock de coquilles SaintJacques en Manche oriental : méthodologie et estimation des indices d'abondance. Rapport Ifremer 40 pp (http://archimer.ifremer.fr/doc/2001/rapport-6550.pdf) 
Visser AW (1997) Using random walk models to simulate the vertical distribution of particles in a turbulent water column. Mar. Ecol. Prog. Ser. 158: 275-281

Wang WX and Xu ZZ (1997) Larval swimming and postlarval drifting behavior in the infaunal bivalve Sinonovacula constricts. Mar. Ecol. Prog. Ser. 148: 71-81 
Table 1: Dispersal Kernel factor for passive transport, variable PLD and variable PLD with swimming behaviour for bay of Saint-Brieuc (a), bay of Seine (b), after 5 days of transport for bay of Saint-Brieuc (c) and bay of Seine (d)

\section{Figure captions}

Fig. 1: Mean wind regime calculated from ARPEGE data (2000-2010) at the point $(0.5 \mathrm{~W} ; 49.5 \mathrm{~N})$. Blue line $=$ wind speed less than $5 \mathrm{~m} / \mathrm{s}$; red line $=$ wind speed between 5 and $10 \mathrm{~m} / \mathrm{s}$; green line: wind speed more than $10 \mathrm{~m} / \mathrm{s}$

Fig. 2: domain of hydrodynamic model (a), spawning areas and contribution of each area for stock in bay of Saint-Brieuc for 1990-1999 (b), for 2000-2010 (c) and in bay of Seine for 2000$2010(d)$

Fig. 3: Results for a spawning date of 8 August 2000 in bay of Saint-Brieuc for Eulerian (a) and Lagrangian (b) transport and for a spawning date of 19 August 2001 in bay of Seine for Eulerian (d) and Lagrangian (e) transport. Mean Lagrangian concentration (= ratio of final number of particles and initial number of particles) and mean Eulerian concentration (micromole/L) for bay of Saint-Brieuc (c) and bay of Seine (f). The larvae from area 1 are red, from area 2 are black, from area 3 are green, from area 4 are blue, from area 5 are pink and from area 6 are cyan

Fig. 4: Mean Bias $\left({ }^{\circ} \mathrm{C}\right)$ between observed and modeled SST in June, July and August 20052006 (a) spatial error and (b) temporal error

Fig. 5: Results of passive transport in bay of Saint-Brieuc for spawning dates of 18 July 2000 (a), 8 August 2000 (b), 3 July 2001 (c) and 24 July 2001 (d). On all figures is represented the progressive vector diagram (provided by ARPEGE analysis) for 34 days; the beginning point is represented by a black point. The larvae from area 1 are red, from area 2 are black, from area 3 are green, from area 4 are blue, from area 5 are pink and from area 6 are cyan

Fig. 6: Mean percentage of larvae that stay in bay of Saint-Brieuc after 34 days of passive transport for all (a), area 4 (b), area 5 (c), area 6 (d) and for results weighted by relative importance of each area (e)

Fig. 7: Results of passive transport in bay of Seine for spawning dates of 17 July 2000 (a), 25 July 2000 (b), 8 July 2006 (c) and 28 June 2003 (d) On all figures is represented the progressive vector diagram (provided by ARPEGE analysis) for 34 days; the beginning point is represented by a black point. The larvae from area 1 are red, from area 2 are black, from area 3 are green, from area 4 are blue and from area 5 are pink

Fig. 8: Mean percentage of larvae that stay in Bay of Seine after 34 days of transport (a) and for results weighted by relative importance of each area (b) 
Fig. 9: mean PLD for the first (left) and second (right) spawning events for bay of Saint-Brieuc (a) and for the first half (left) and second half of spawning dates for bay of Seine (b)

Fig. 10: Comparison between results of passive transport (left), variable PLD (middle) and swimming (right) in bay of Saint-Brieuc for spawning dates of 3 July 2001 (a), 18 June 2005 (b) and 30 July 2007 (c). The larvae from area 1 are red, from area 2 are black, from area 3 are green, from area 4 are blue, from area 5 are pink and from area 6 are cyan

Fig. 11: Comparison between results of passive transport (left), variable PLD (middle) and swimming (right) in bay of Seine for spawning dates of 17 August 2006 (a), 7 August 2007 (b) and 15 August 2007 (c). . The larvae from area 1 are red, from area 2 are black, from area 3 are green, from area 4 are blue and from area 5 are pink

Fig. 12: Mean percentage of larvae that stay in bay of Saint-Brieuc after variable PLD (a), for results weighted by relative importance of each area (b), in bay of Seine after variable PLD (c), for results weighted by relative importance of each area (d)

Fig. 13: Larvae distribution on water column in bay of Seine for a spawning date of 17 August 2006 for area 5 for passive transport (a) and swimming behavior (b) after 5 days (left), 15 days (middle) and 25 days (right) 


\begin{tabular}{|c|c|c|c|c|c|c|}
\hline \multicolumn{3}{|c|}{ Passive Transport } & PLD & & PLD + SB & \\
\hline Area & D & I & D & I & D & I \\
\hline $\mathbf{1}$ & 25,63 & 0,05 & 24,23 & 0,05 & 27,17 & 0,07 \\
\hline $\mathbf{2}$ & 26,00 & 0,05 & 22,70 & 0,03 & 24,95 & 0,05 \\
\hline $\mathbf{3}$ & 28,95 & 0,05 & 25,03 & 0,04 & 23,80 & 0,08 \\
\hline $\mathbf{4}$ & 11,35 & 0,05 & 9,15 & 0,04 & 7,58 & 0,06 \\
\hline $\mathbf{5}$ & 10,79 & 0,02 & 7,53 & 0,03 & 9,27 & 0,05 \\
\hline $\mathbf{6}$ & 10,58 & 0,01 & 7,88 & 0,01 & 7,94 & 0,03 \\
\hline
\end{tabular}

\begin{tabular}{|c|c|c|c|c|c|c|}
\hline \multicolumn{3}{|c|}{ Passive Transport } & PLD & PLD + SB \\
\hline Area & D & I & D & I & D & I \\
\hline $\mathbf{1}$ & 59,40 & 0,15 & 53,96 & 0,19 & 55,32 & 0,23 \\
\hline $\mathbf{2}$ & 58,48 & 0,11 & 54,06 & 0,18 & 51,15 & 0,17 \\
\hline $\mathbf{3}$ & 50,55 & 0,09 & 32,24 & 0,11 & 34,81 & 0,13 \\
\hline $\mathbf{4}$ & 42,19 & 0,12 & 26,30 & 0,15 & 30,72 & 0,19 \\
\hline $\mathbf{5}$ & 65,05 & 0,09 & 38,98 & 0,08 & 40,13 & 0,10 \\
\hline
\end{tabular}

b

\begin{tabular}{|c|c|c|c|c|}
\hline & \multicolumn{2}{|c|}{ Passive Transport } & \multicolumn{2}{c|}{ SB } \\
\hline Area & D & I & D & I \\
\hline $\mathbf{1}$ & 6,45 & 0,2 & 7,11 & 0,19 \\
\hline $\mathbf{2}$ & 4,15 & 0,08 & 4,81 & 0,07 \\
\hline $\mathbf{3}$ & 3,55 & 0,28 & 4,22 & 0,03 \\
\hline $\mathbf{4}$ & 3,07 & 0,07 & 3,67 & 0,06 \\
\hline $\mathbf{5}$ & 4,21 & 0,13 & 4,86 & 0,10 \\
\hline $\mathbf{6}$ & 3,18 & 0,08 & 3,38 & 0,06 \\
\hline
\end{tabular}

\begin{tabular}{|c|c|c|c|c|}
\hline & \multicolumn{2}{|c|}{ Passive Transport } & \multicolumn{2}{c|}{ SB } \\
\hline Area & D & I & D & I \\
\hline $\mathbf{1}$ & 22,42 & 0,40 & 23,00 & 0,38 \\
\hline $\mathbf{2}$ & 26,40 & 0,46 & 27,53 & 0,44 \\
\hline $\mathbf{3}$ & 13,17 & 0,22 & 13,93 & 0,18 \\
\hline $\mathbf{4}$ & 13,18 & 0,36 & 14,57 & 0,34 \\
\hline $\mathbf{5}$ & 16,68 & 0,21 & 17,70 & 0,20 \\
\hline
\end{tabular}




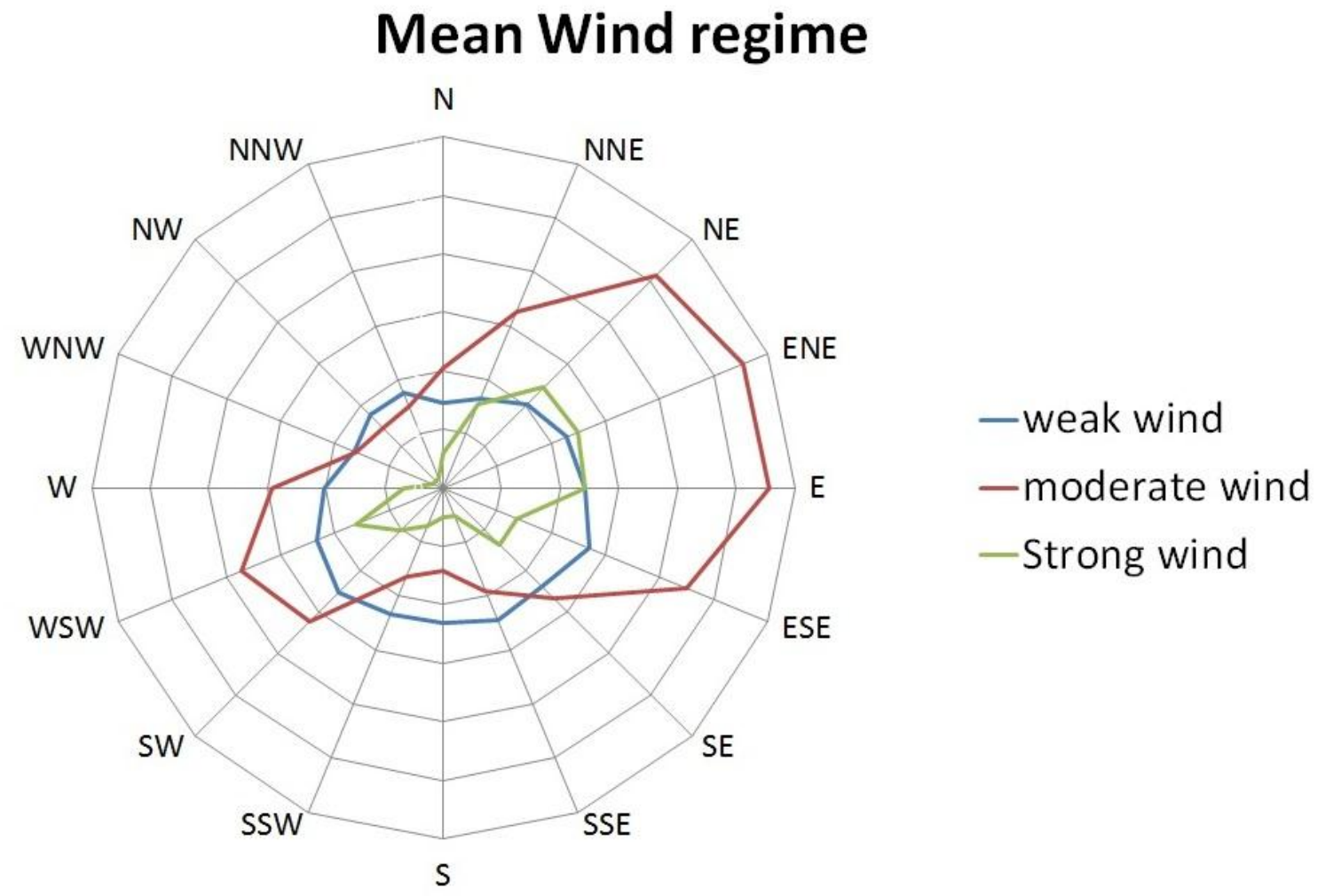




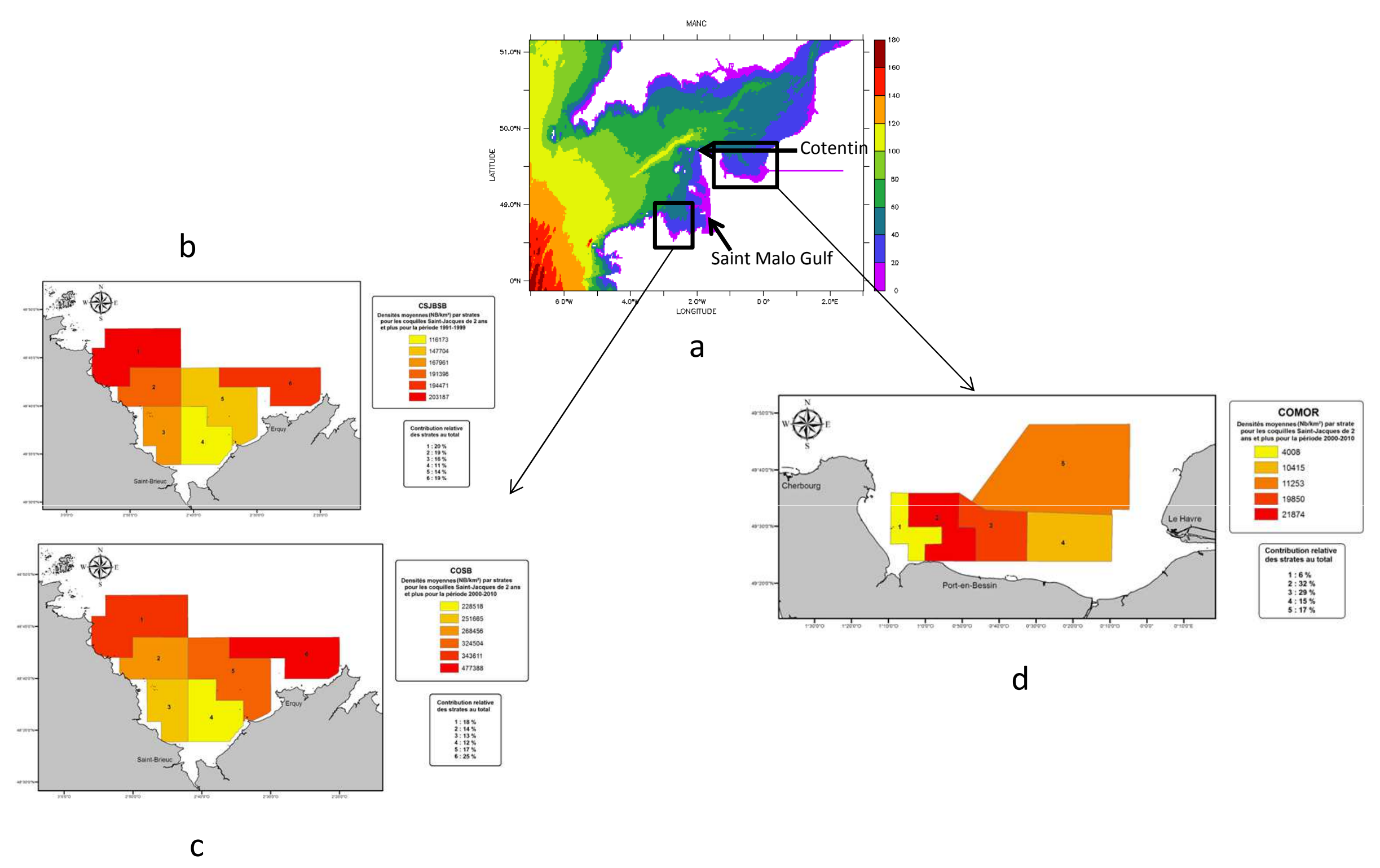




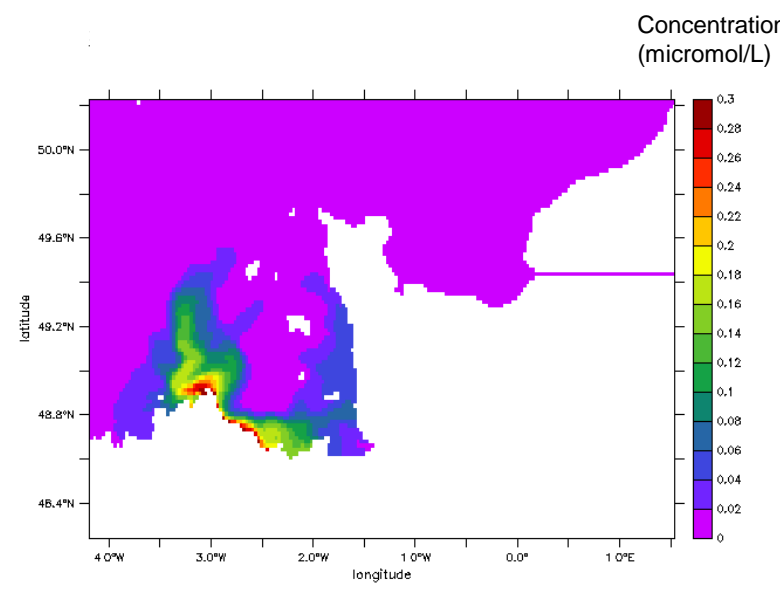

a

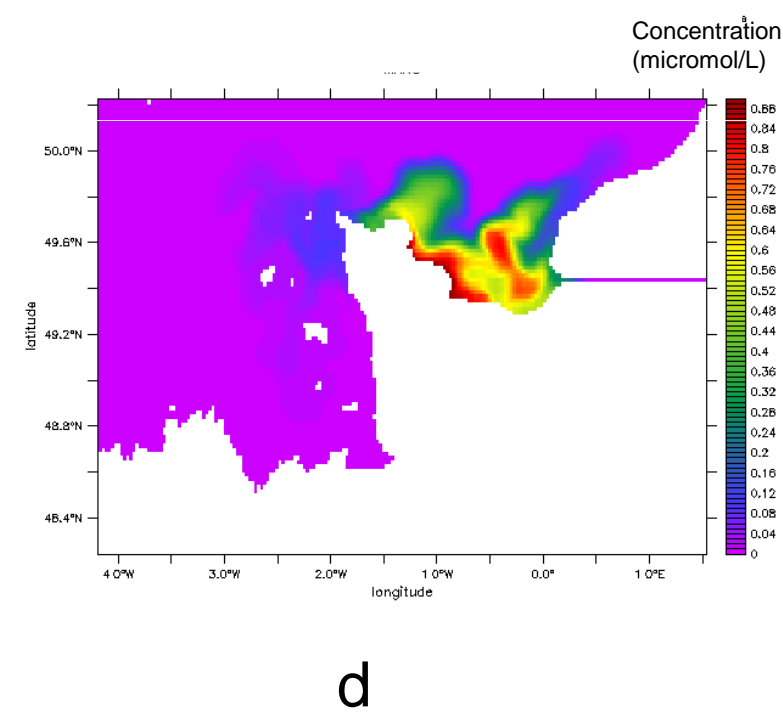

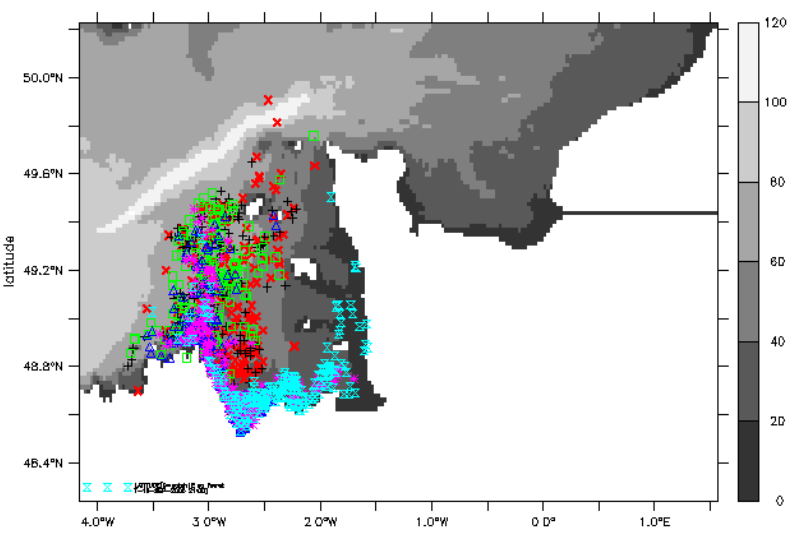

b

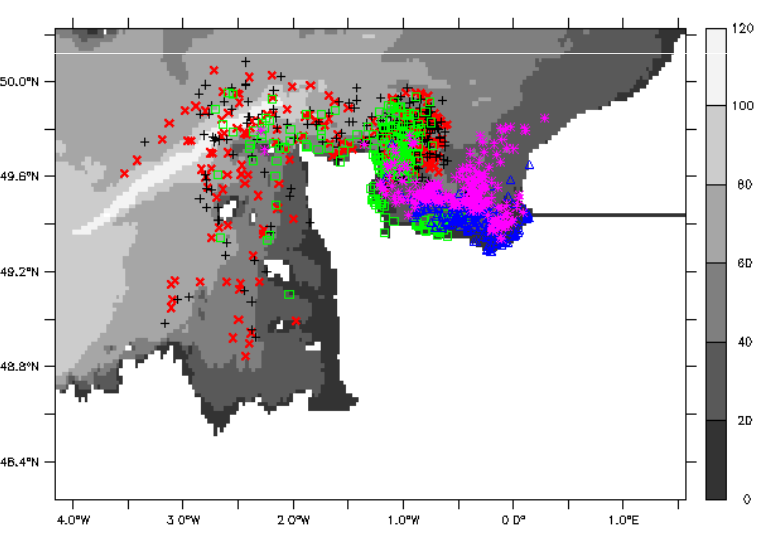

e

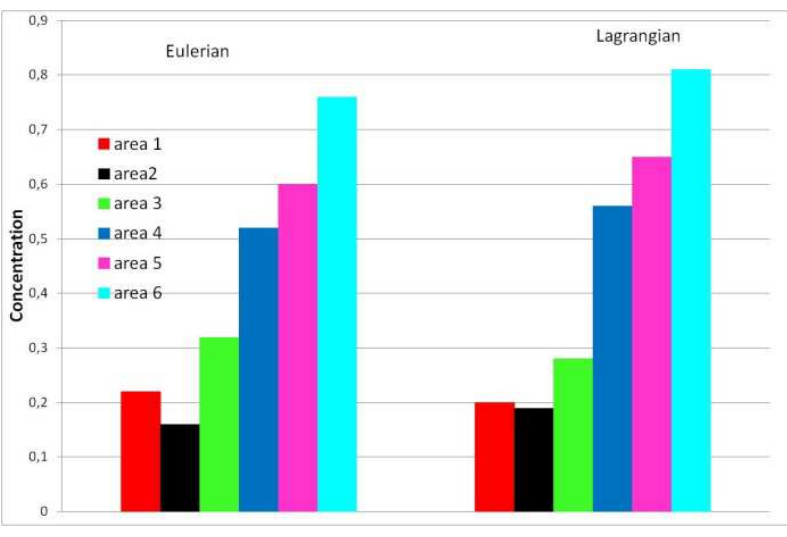

C

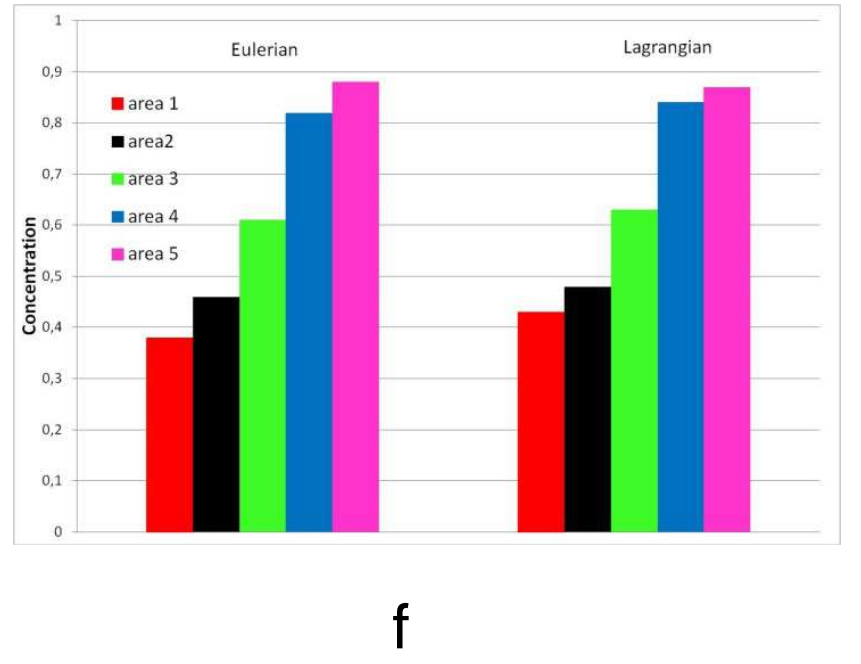



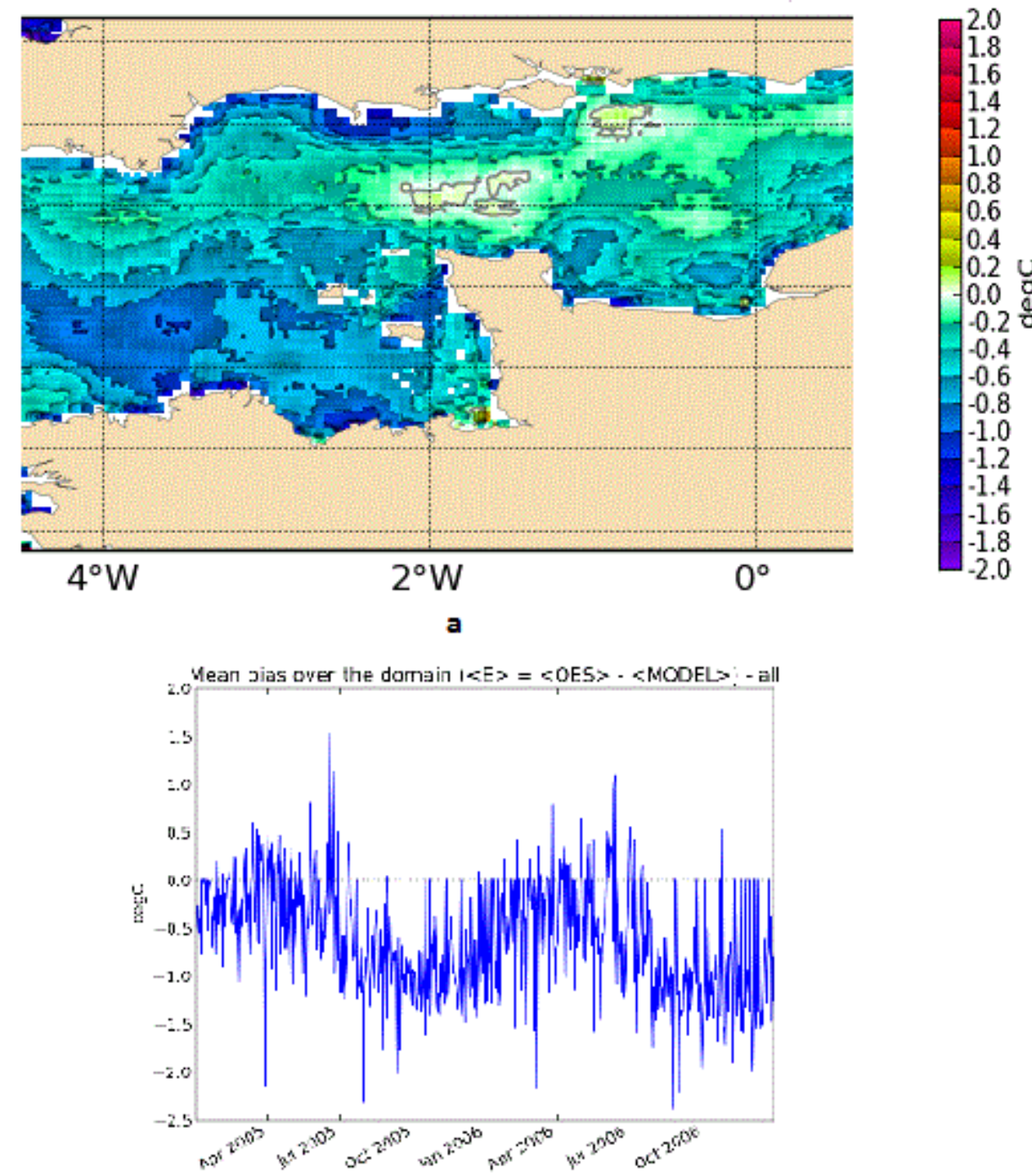

b 

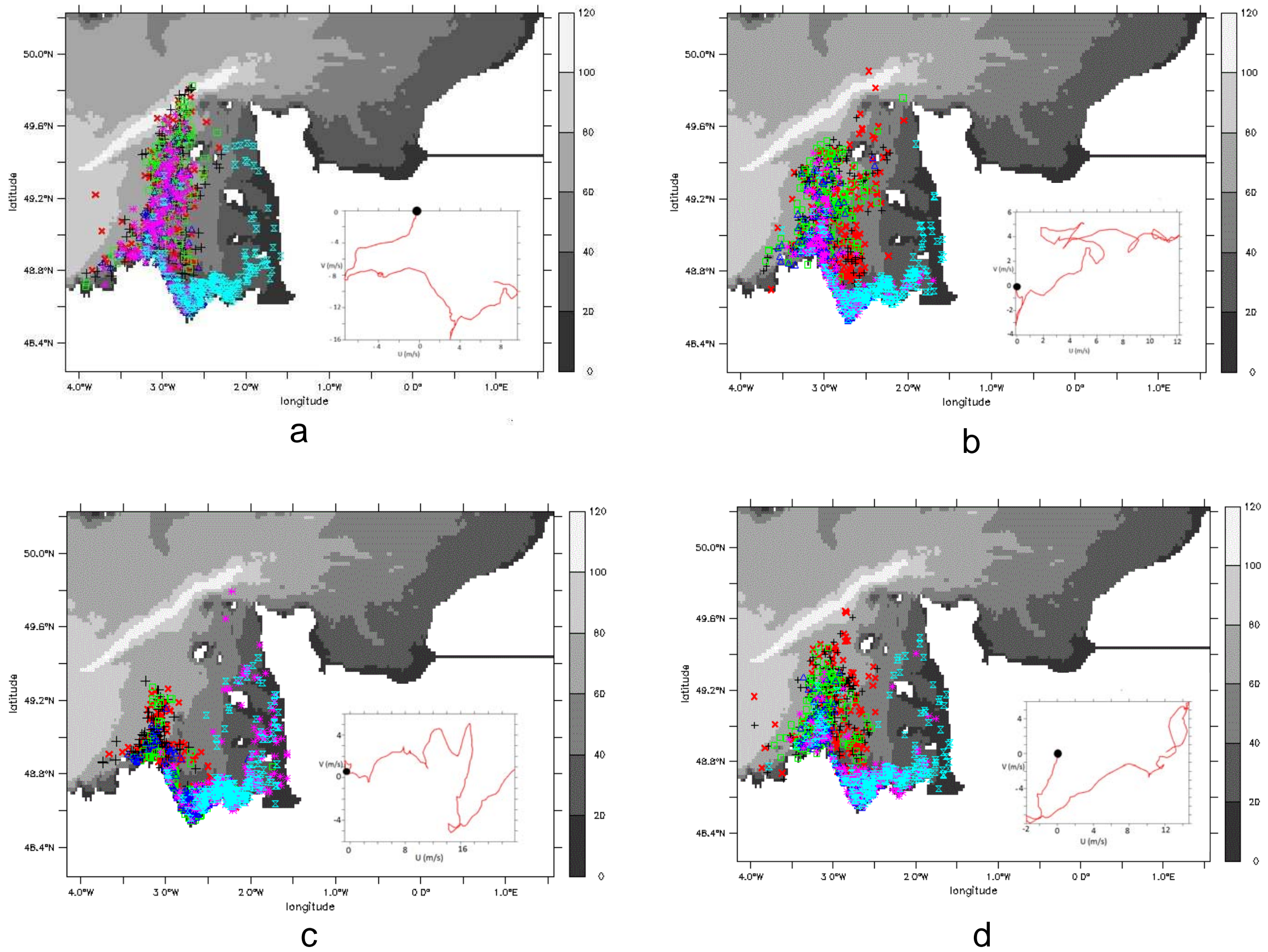


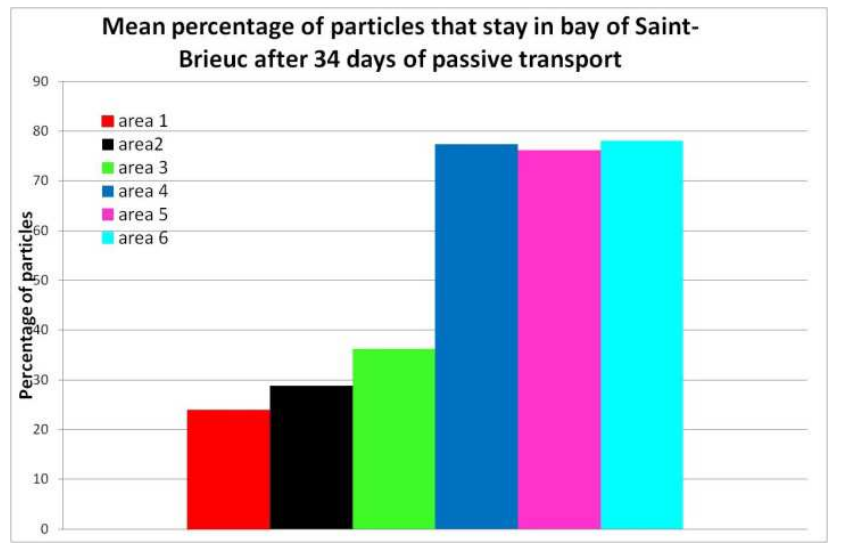

a

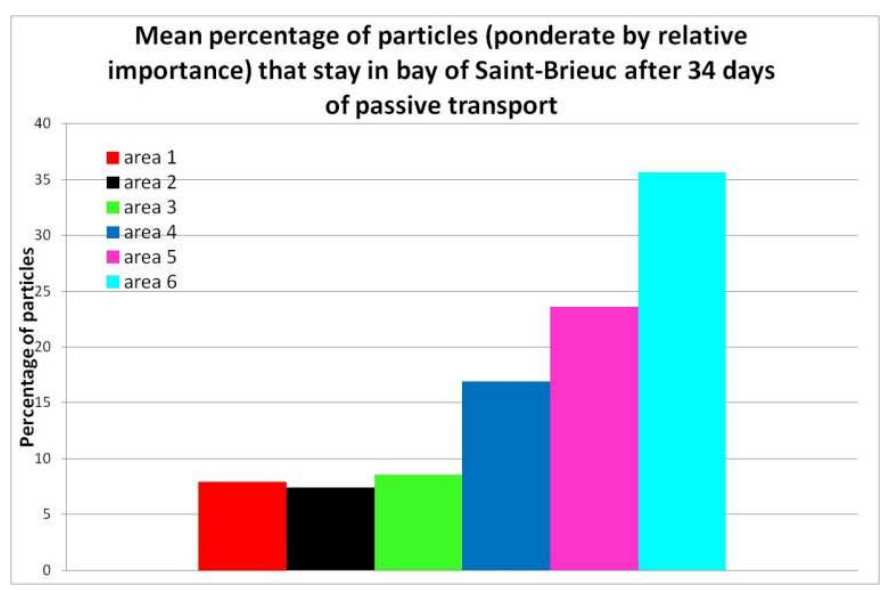

Mean percentage of particles of area 4 that stay in bay of Saint-Brieuc after 34 days of passive transport

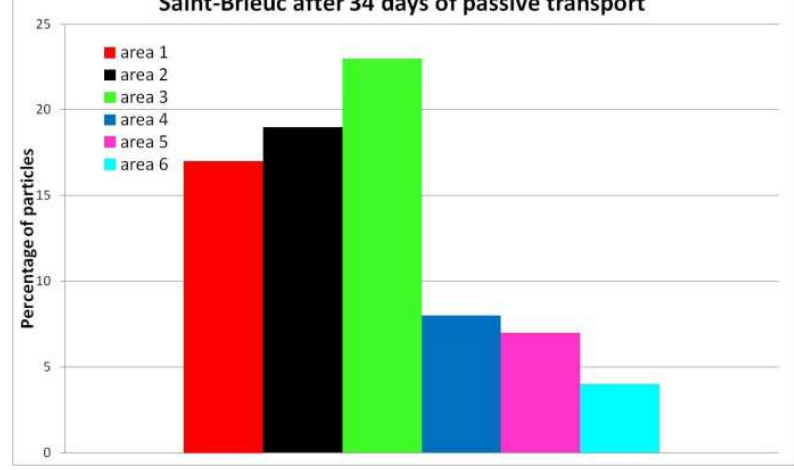

b

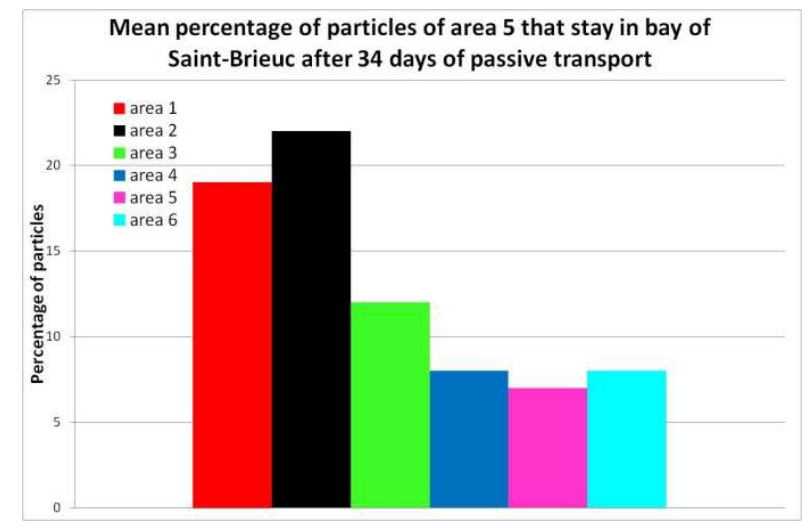

C

Mean percentage of particles of area 6 that stay in bay of Saint-Brieuc after 34 days of passive transport

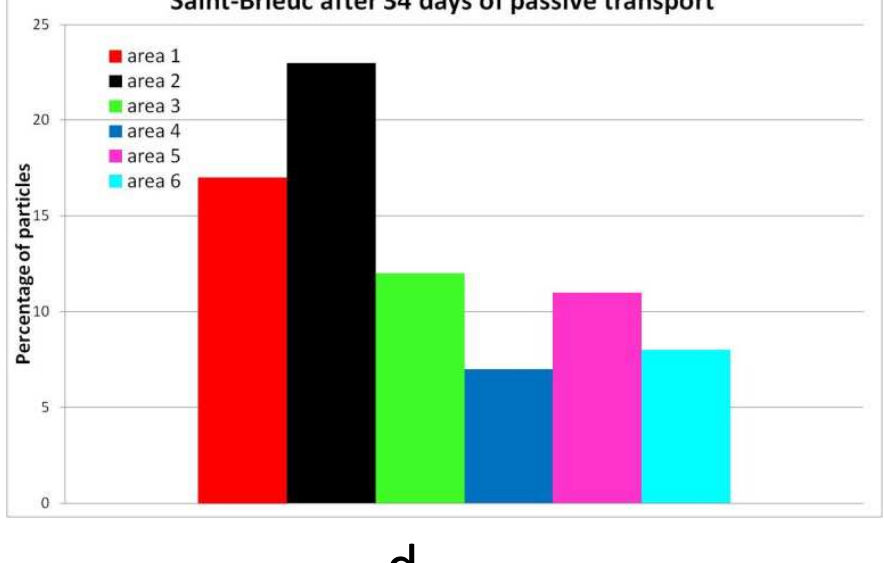

d 

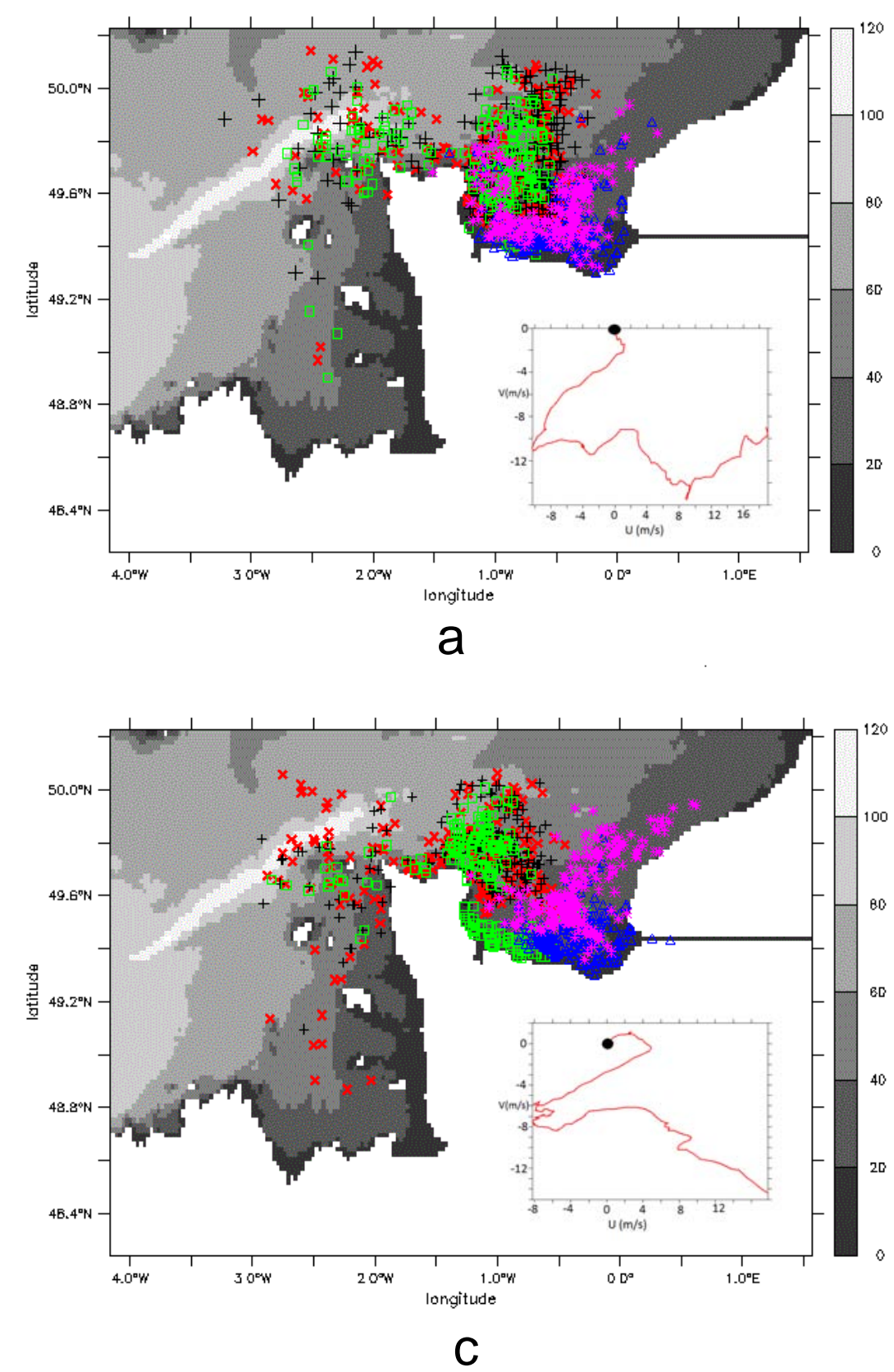
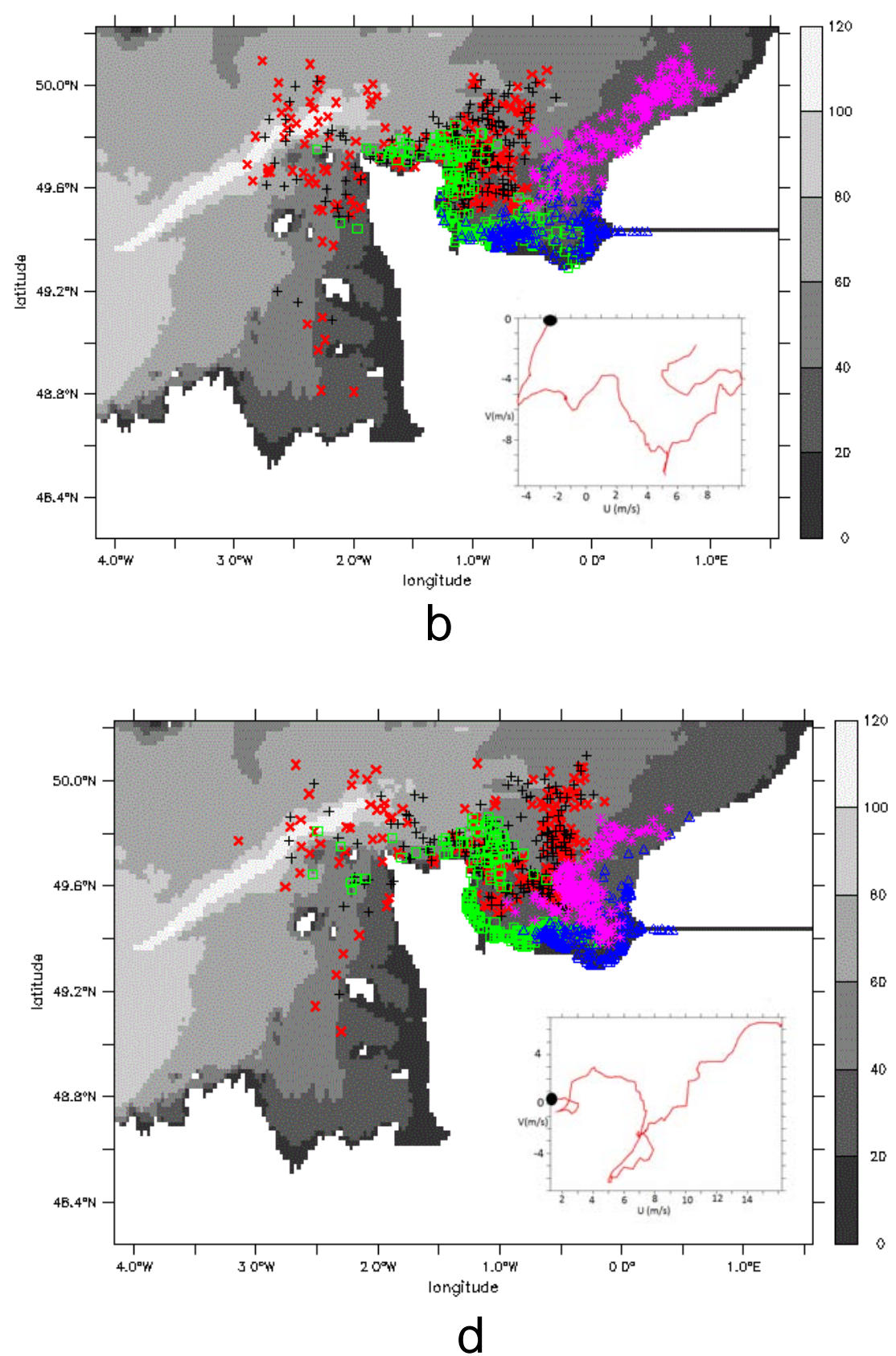


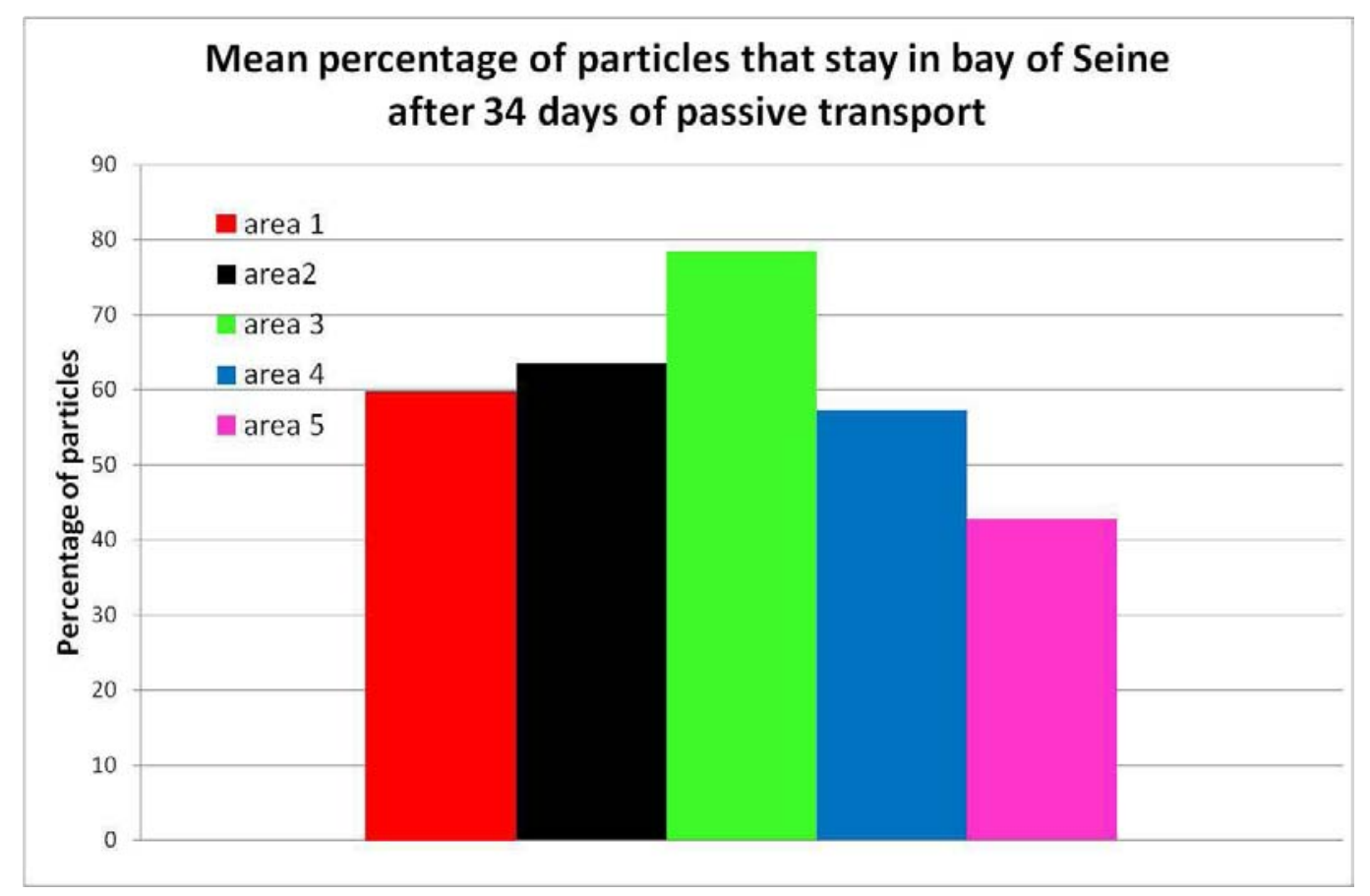

a

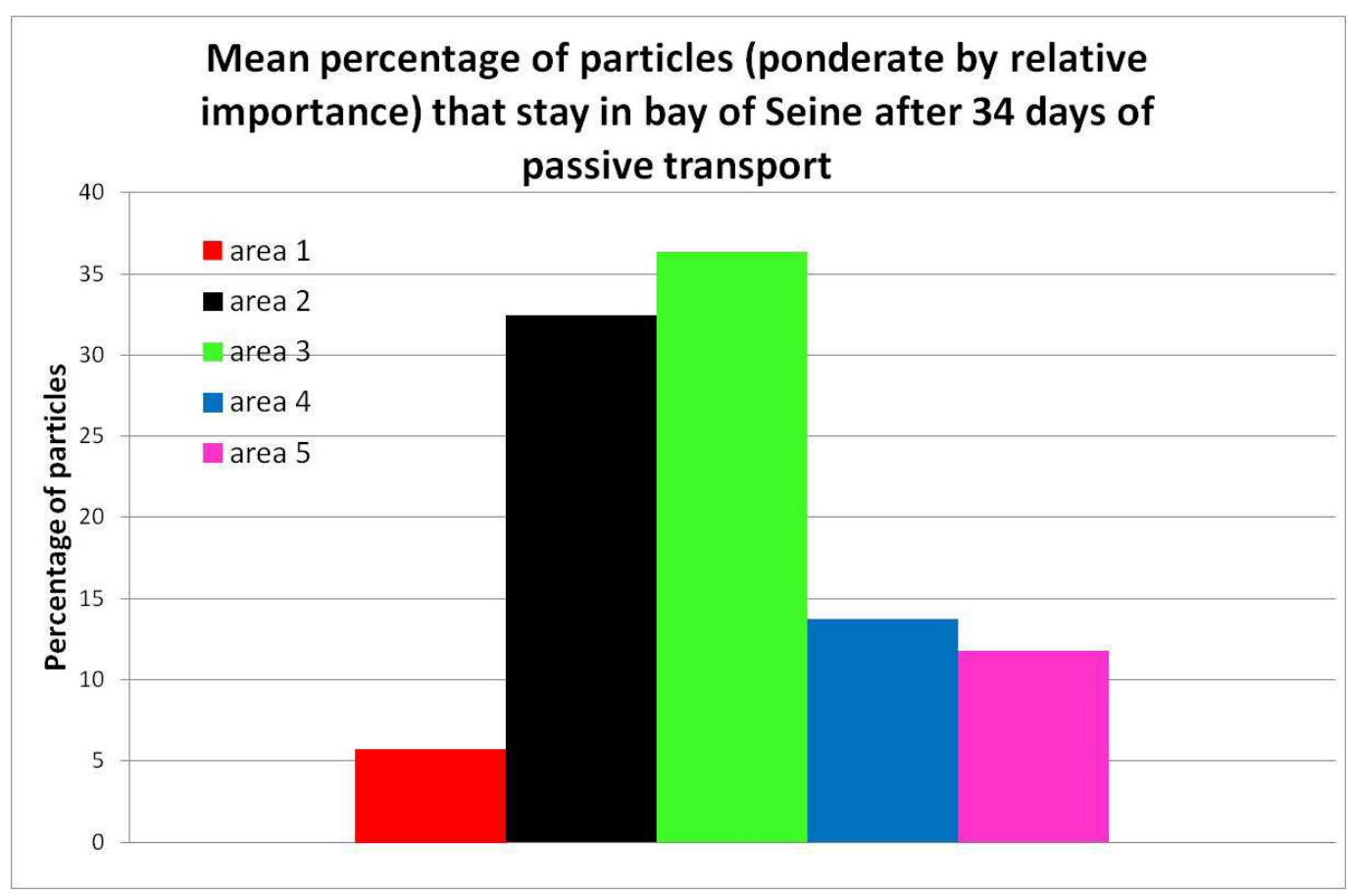

b 


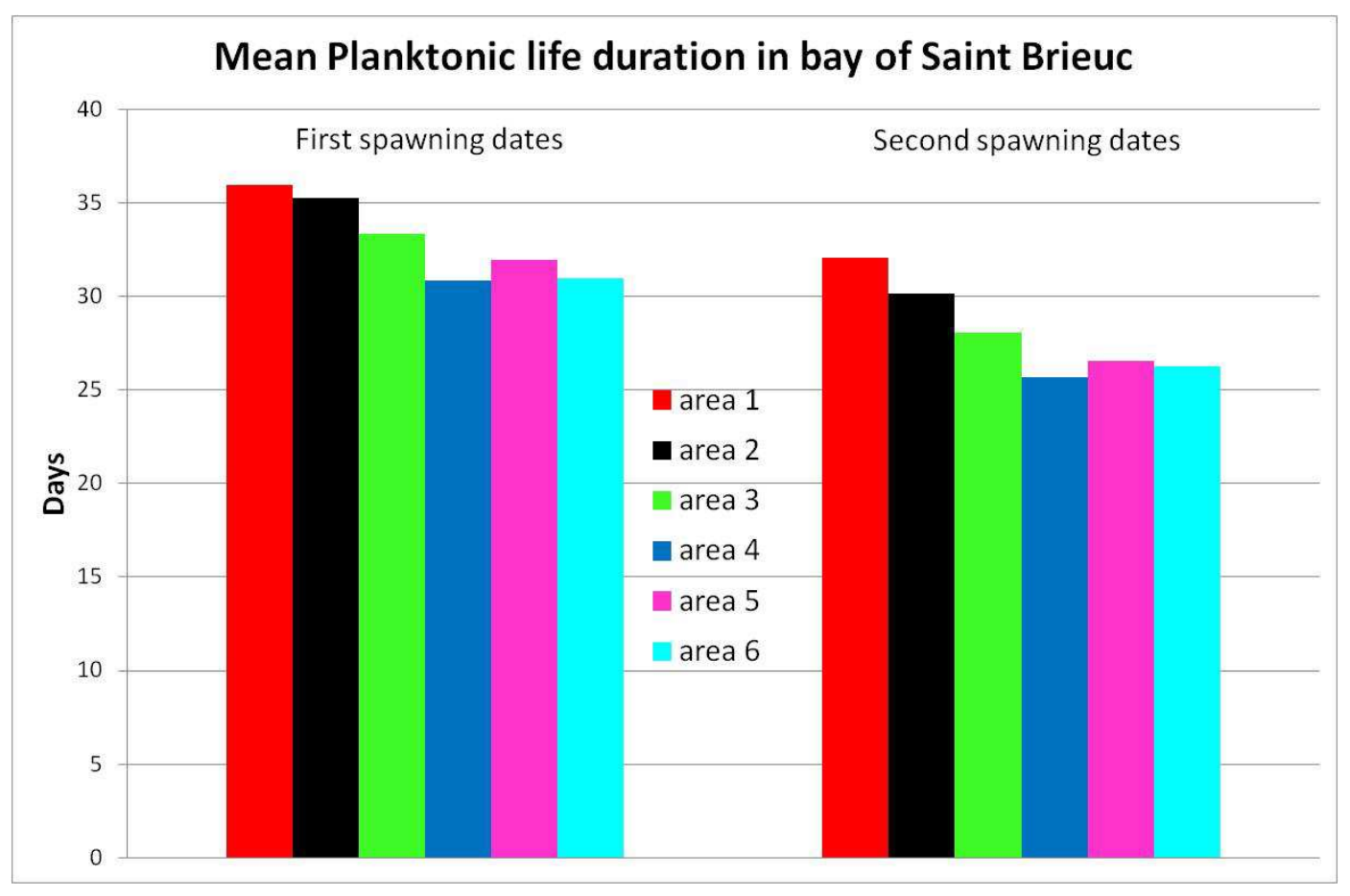

a

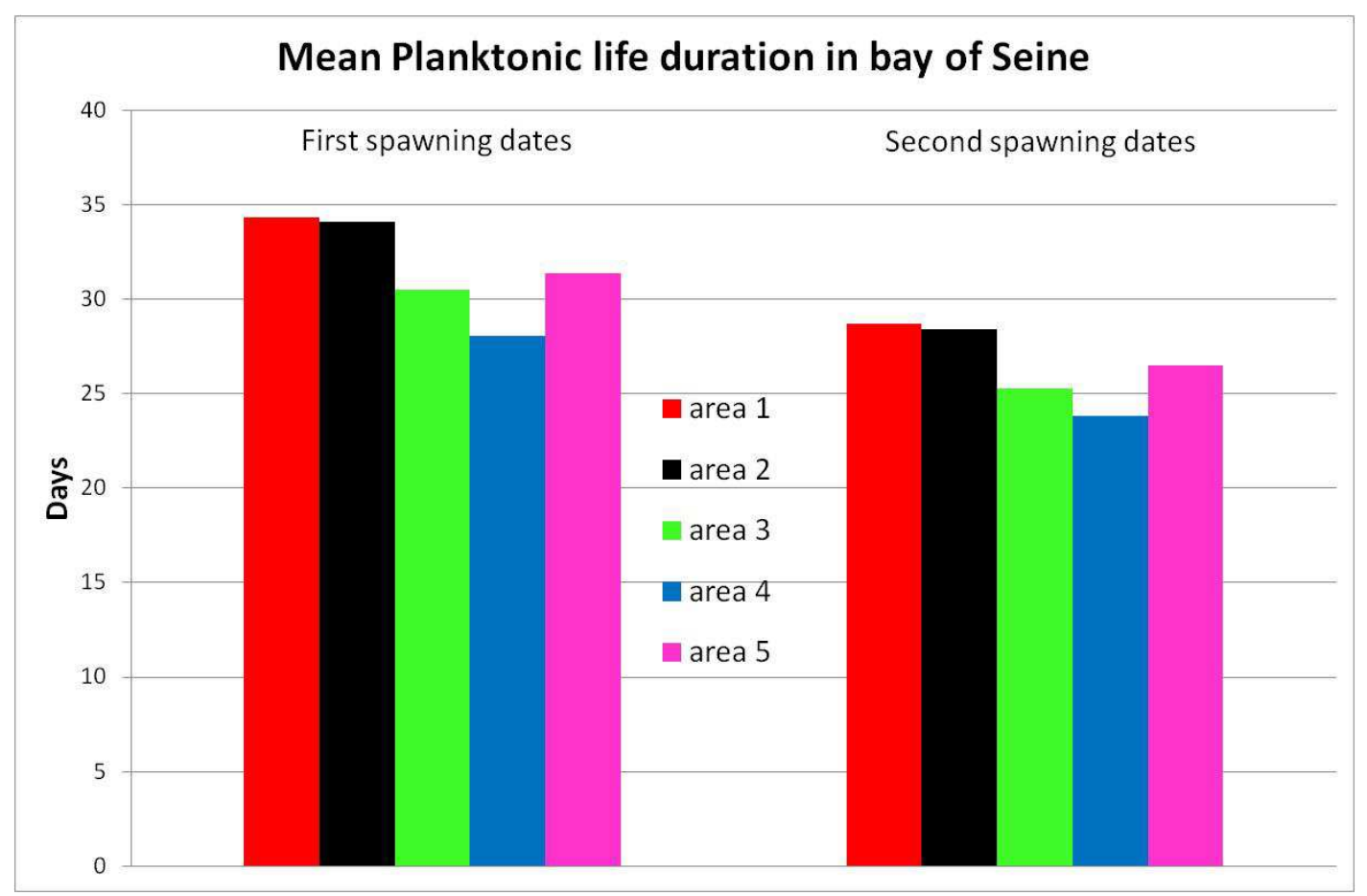

b 

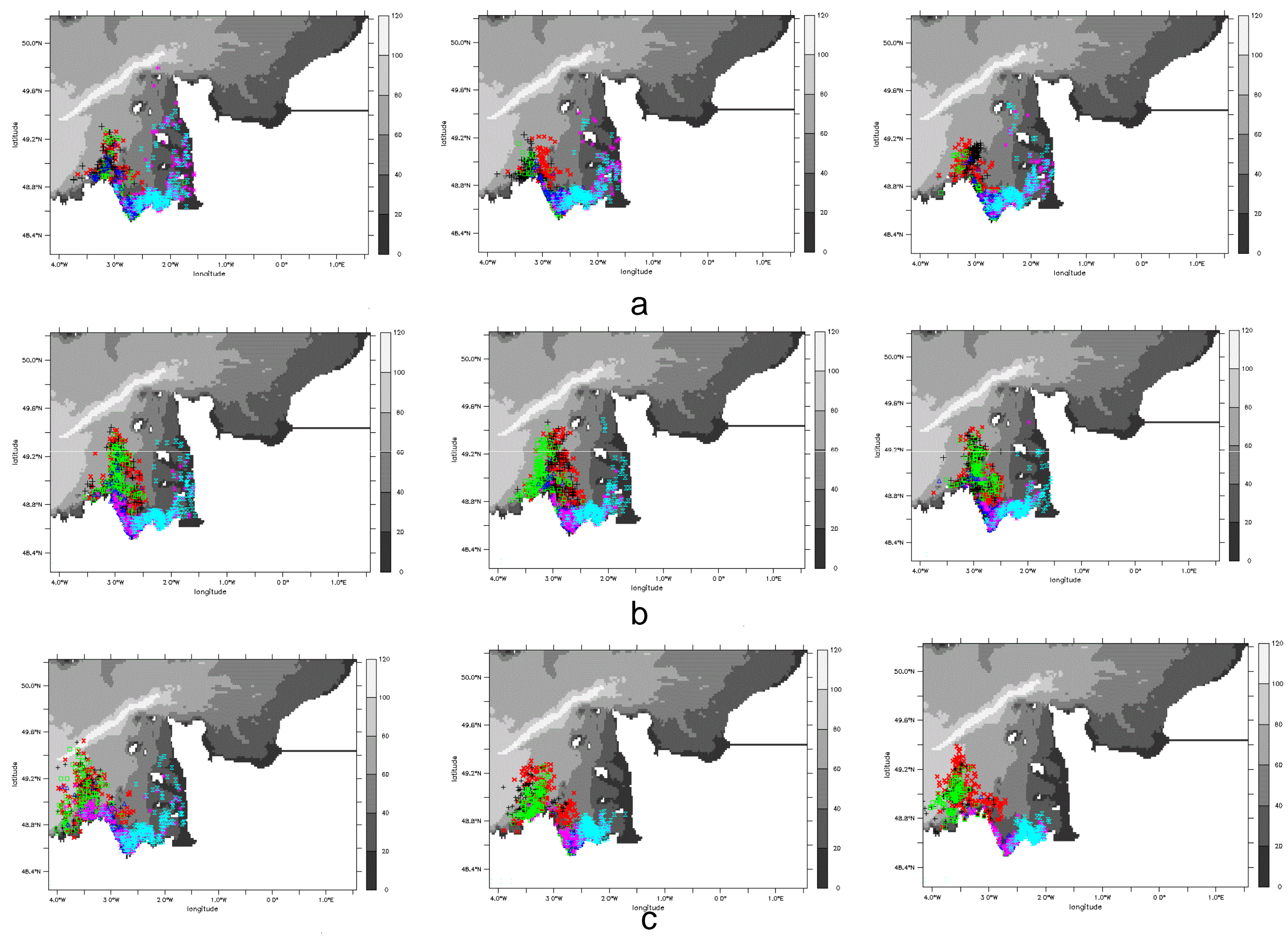

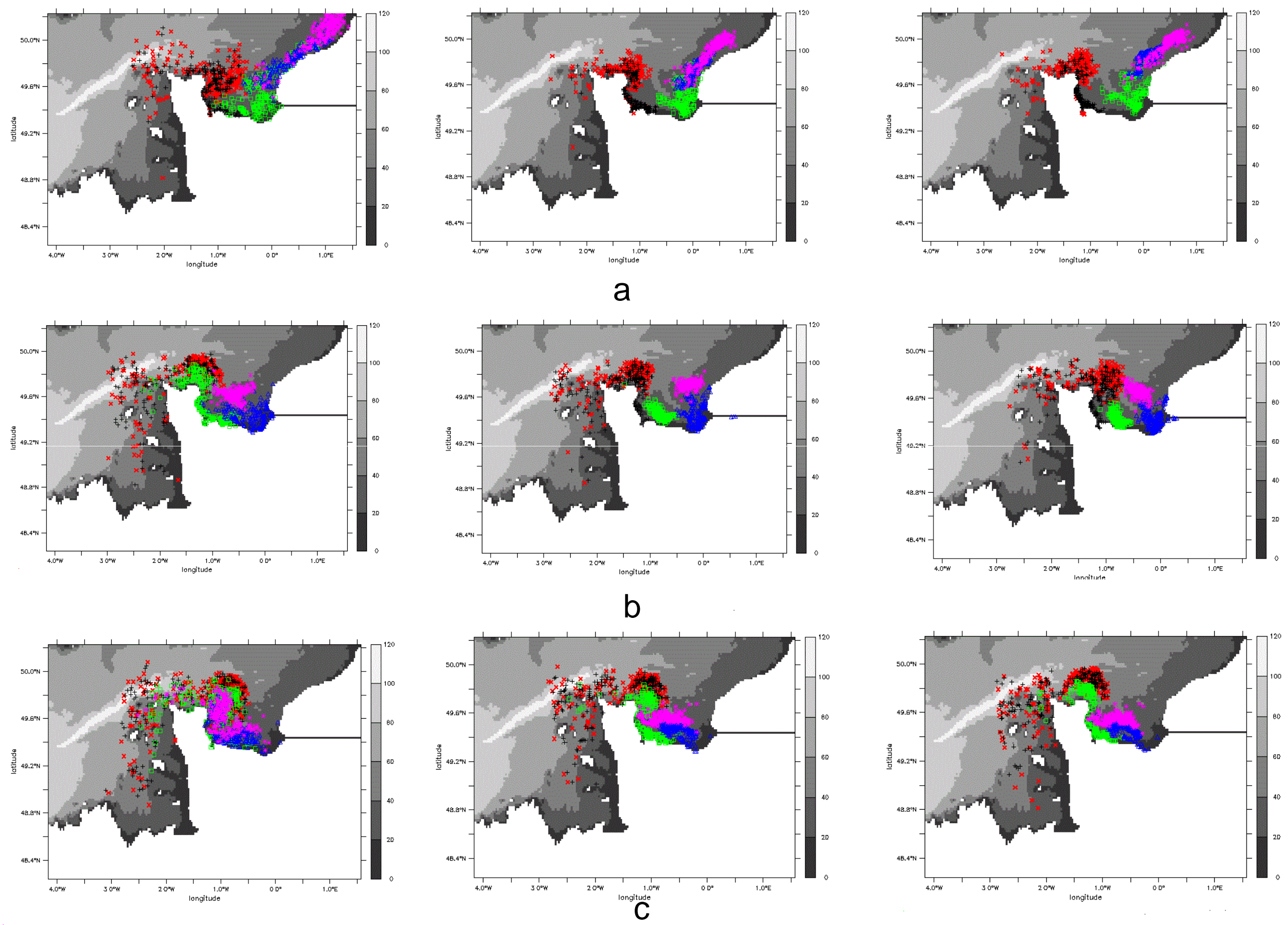


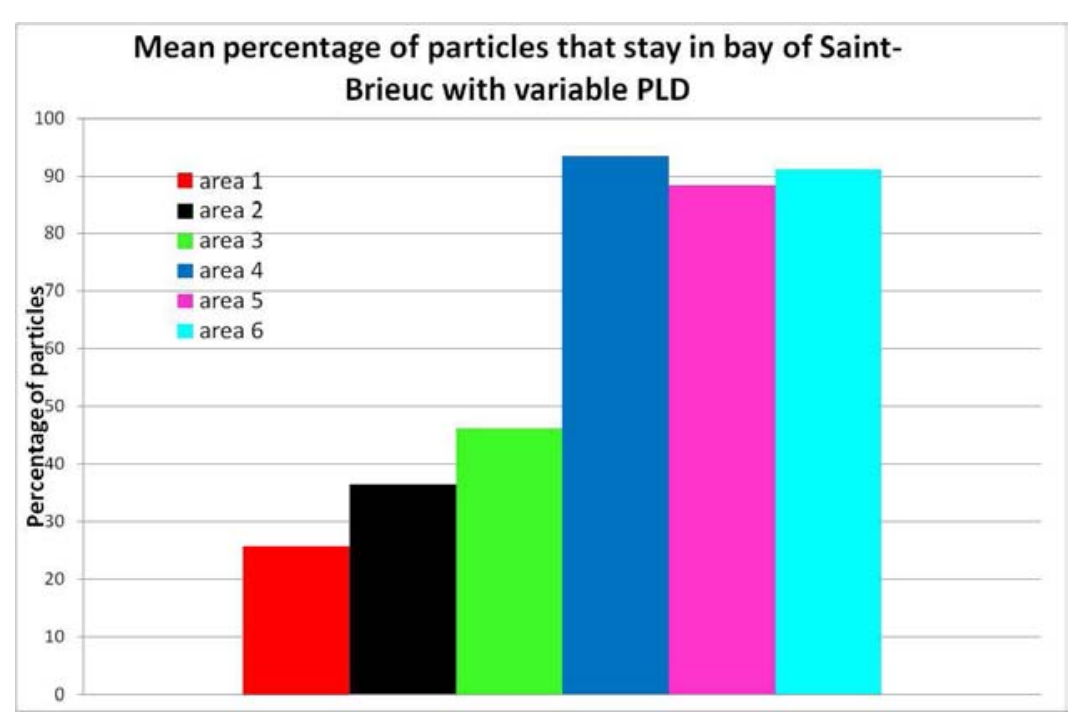

a

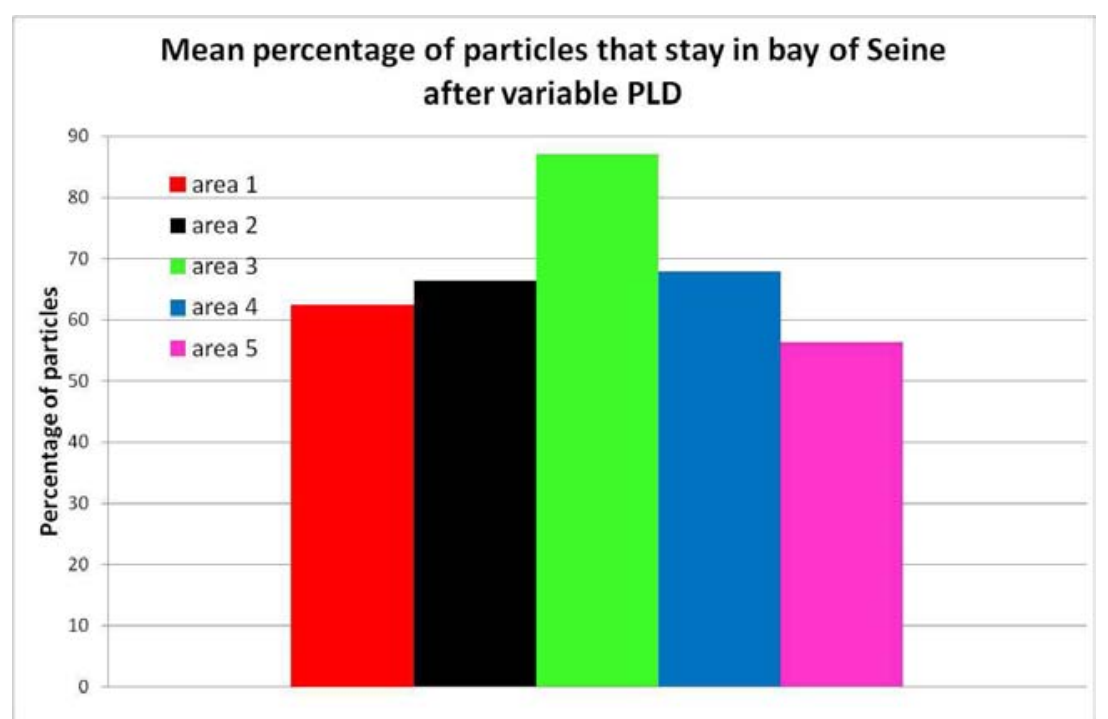

Mean percentage of particles (ponderate by relative importance) that stay in bay of Saint-Brieuc with variable PLD

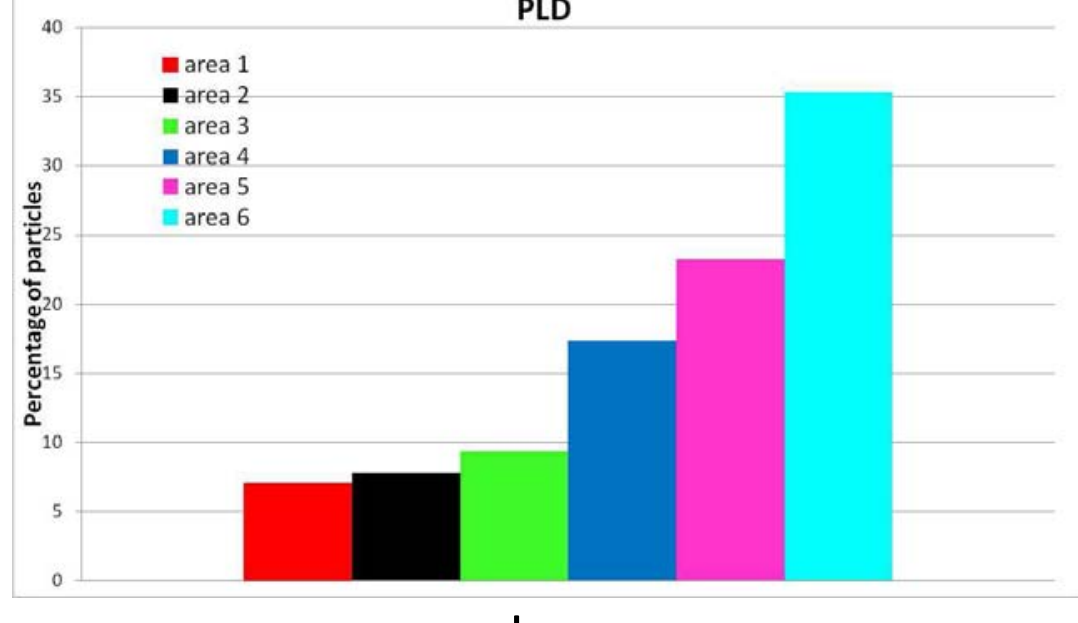

b

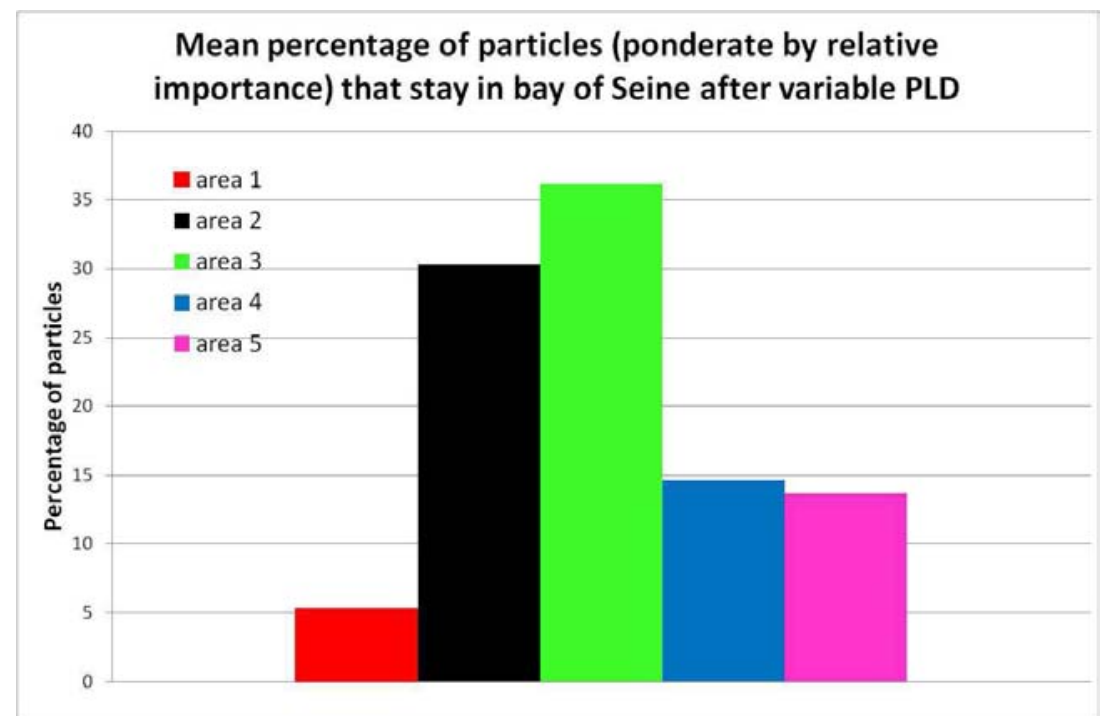

d 

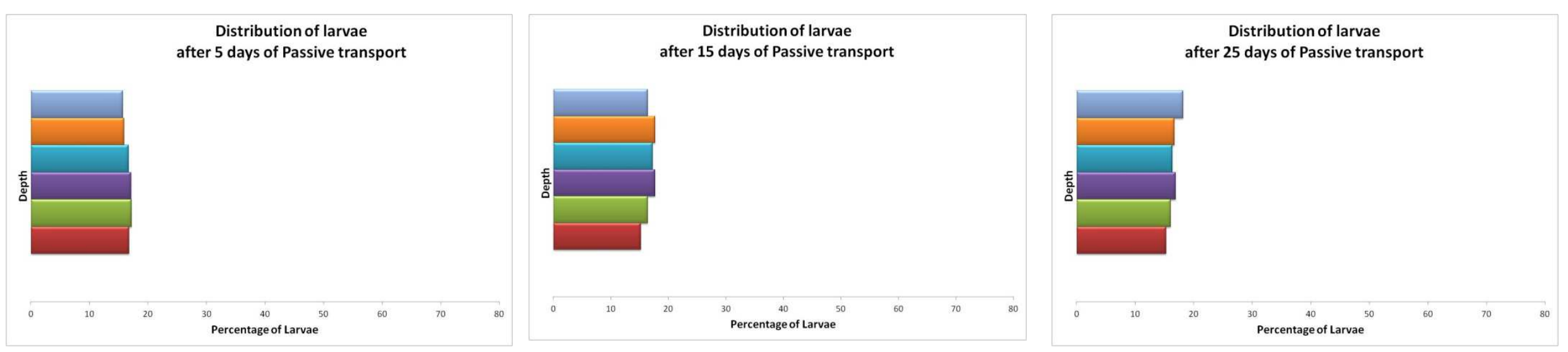

a
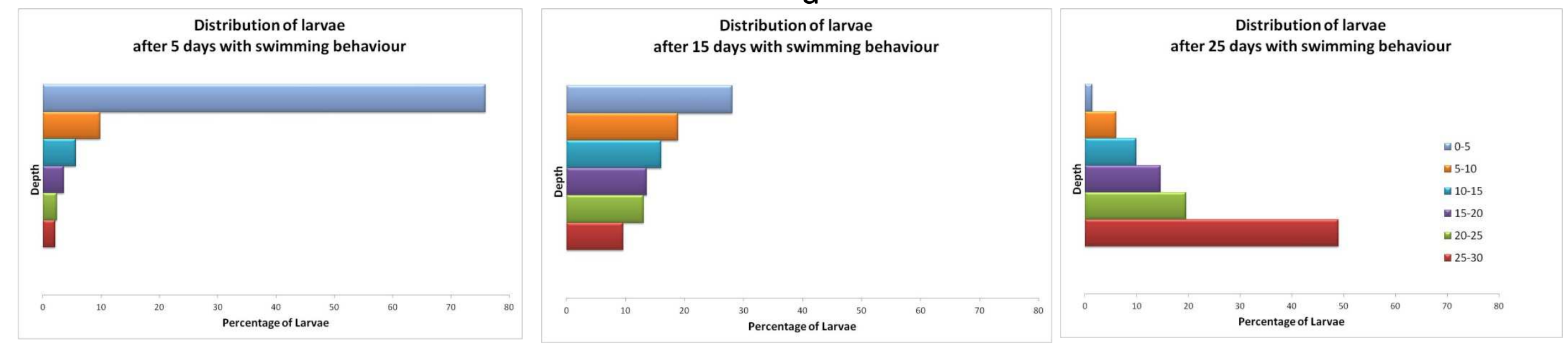